\title{
A nonlinear perturbation study of a shoreface nourishment on a multiply barred beach
}

\author{
W.L. Chen, ${ }^{a, 1, *}$, N. Dodd ${ }^{a}$ \\ ${ }^{a}$ Faculty of Engineering, University of Nottingham, Nottingham NG7 2RD, UK.
}

\begin{abstract}
The 1D (cross-shore) nonlinear nourishment-as-a-perturbation model of Chen and Dodd (2019) is extended to include wave streaming and depth-varying mean return flow. This is shown to lead to physically consistent values for the migration rate of small amplitude bed perturbations in the whole nearshore region. The model is also extended to arbitrary wave incidence angle, and an alternative energy dissipation description is included. The model is applied to a background profile that includes multiple nearshore bars, and which also allows comparison with observations of nourishment development and migration. The chosen profile is that of the Terschelling shoreface nourishment. Over the initial nourishment region the linearised bed evolution equation predicts onshore small-amplitude bed perturbation migration rates in the troughs (where waves shoal) and offshore rates on the bars (where waves break). Sensitivity studies using the fully nonlinear model reveal wave height to be the primary controlling parameter for the resultant perturbed sediment flux. Perturbed sediment fluxes are onshore up to a threshold wave height; beyond this offshore fluxes predominate. Wave period and angle of incidence, and tide level are all secondary controlling factors, variation in which yields no change in perturbed sediment flux sign (for fixed wave height). Recorded wave and tide signals are used to drive the model to simulate six months of the initial nourishment evolution. It is shown that in calmer conditions the small amplitude migration rate of bed disturbances is a highly accurate predictor of the fully nonlinear migration rate (as described by the centre of mass of the nourishment); in storm periods the two predictors diverge. The observed overall migration rate is well described
\end{abstract}

\footnotetext{
*Corresponding author, wenlong.chen@cranfield.ac.uk

${ }^{1}$ The present affiliation of the author is: School of Water, Energy and Environment, Cranfield University
}

Preprint submitted to Elsevier

November 19, 2020 
by the model. The details of the profile evolution show a moderately good reproduction of those observed (Brier Skill Score $=0.52$ ).

Keywords: nonlinear perturbation model, Terschelling nourishment, wave skewness, wave driven current, streaming effect

\section{Introduction}

Shoreface nourishments are adopted to mitigate the effect of erosion problems along coastlines (Hamm et al. 2002). They are thought to be cheaper, more flexible in execution and more friendly to the environment than traditional hard coastal structures (Capobianco et al. , 2002). The method has been pioneered in the Netherlands. Since 1990, dozens of shoreface nourishments have been performed (Hillen and Roelse, 1995).

Understanding the temporal and spatial evolution of a shoreface nourishment is important, because it allows us to design them most effectively. Complex morphodynamical models are used by coastal engineers to predict this evolution, with reasonable success (e.g. Grunnet et al., 2004). A disadvantage of using such a model is that they are computationally expensive to run. Furthermore, in complex models, the nourishment evolution is embedded in the dynamics of the total morphology, which thus must be disentangled from the "background" morphodynamics in order to understand it. Moreover, we are at present unable to predict those background morphodynamics because presentday complex models are unable to predict so-called beach recovery van Rijn et al. 2013), which is the gradual onshore sediment movement under prevailing milder wave conditions.

To circumvent these problems Chen and Dodd (2019) developed an approach that can be described as a "nourishment-as-a-perturbation" (hereafter NaaP) concept. In this approach they focus on the dynamics of the nourishment alone (i.e. the perturbation), and presented a 1D (cross-shore) nonlinear evolution model for the nourishment. In their study, on an idealised, plane beach, sediment flux is driven by wave skewness, wave asymmetry and mean current (return flow and tide), which are three of the main physical processes thought to be responsible for cross-shore sediment movement (Roelvink and Reniers, 2011). Because the nourishment alters the sea bed profile, the hydrodynamics and hence the sediment flux are also altered. The divergence of this perturbed sediment flux, i.e., the difference between the sediment fluxes with and without the 
nourishment, then drives the evolution of the nourishment. The nourishment is additionally subject to down-slope diffusion under gravity. In this way, it is the difference between the sediment flux of the nourished and un-nourished beach that is of prime importance, rather than the absolute value, which obviates the need for accurate reproduction of beach recovery.

Thus, the dynamics of the nourishment are isolated, which potentially offers us a better understanding of their behaviour, as long as the background morphology does not evolve too drastically. A related method was applied by $D e$ Swart and Calvete (2003) to study the nonlinear evolution of human interventions on shoreface-connected sand ridges, by van Leeuwen et al. (2007) to study the linear evolution of a shoreface nourishment, and by Roos et al. (2008) to examine sand extractions. Roos and Hulscher (2003) also provided a general linear framework of looking at bed evolution as a perturbation problem. Model results of Chen and Dodd (2019) are consistent with observations, as well as prevailing theory on cross-shore sediment transport.

However, the study of Chen and Dodd (2019) was limited to an idealised, plane beach. For the concept to be useful, it must be valid for non-planar beaches, on which there may be multiple regions of breaking and shoaling, aside from the nourishment itself. Equally, it must be applicable to real beaches, on which the background profile is, notionally, evolving, at least for a limited duration.

We therefore present here a study, in which the nonlinear NaaP model of Chen and Dodd (2019) is applied to a real beach that possesses a multiple barred background profile on which a nourishment is placed. To do this we must also develop further the NaaP approach so as to include wave streaming, which is thought to play an important role in cross-shore sediment flux (Fuhrman et al. 2009). Furthermore, the description of mean-current-driven cross-shore sediment flux of Chen and Dodd (2019) is depth-invariant, so that at deeper depths the mean near-bed sediment flux is likely to be overestimated. Therefore, we extend that approach so as to be more realistic. These two developments are also important because accurate sediment fluxes also provide accurate reproduction of nourishment kinematics, which allows us to consider nourishment migration speed separately from bed change.

For the application we choose the Terschelling nourishment. This field case is of a quasi-alongshore uniform background cross-shore profile that consists of a number of bars, on which an extended, shore-parallel nourishment was placed. To this end we also amend the approach of Chen and Dodd (2019) so as to utilise 
an alternative wave energy description, and to include oblique wave incidence.

In this application we seek to capture the nourishment morphodynamics and kinematics, rather than perform a model validation.

In the next section we present the NaaP model, with a focus on the new dynamics included. We then investigate the implications of these changes to the approach. Next we present a description of the Terschelling nourishment study case. We then present a sensitivity study of the site using the NaaP approach. Model simulations of the Terschelling nourishment are then presented and analysed. Finally, a discussion is presented, and conclusions are drawn.

\section{Methodology}

The (1D) nonlinear perturbation model for the cross-shore evolution of a shoreface nourishment proposed by Chen and Dodd (2019) is the basis for the present study. The model couples wave, tide and sediment dynamics, and focuses on the perturbed dynamics introduced by the nourishment. The reader is referred to Chen and Dodd (2019) for a full investigation of the earlier version of the model for a idealised nourishment on a plane beach.

Here we present the new model equations. These include the dynamical equations, and the equations parameterizing the processes.

\subsection{The model equations}

\subsubsection{The evolution equation of the nourishment}

The change in bed level with respect to the pre-nourishment (basic) alongshoreuniform profile, is denoted $b(x, t)$. It is determined from the sediment conservation equation

$$
\frac{\partial b}{\partial t}+\frac{1}{1-p} \frac{\partial q^{\prime}}{\partial x}-\gamma \frac{\partial^{2} b}{\partial x^{2}}=0
$$

where $p=0.4$ is the porosity of the sediment. $x$ is the cross-shore spatial, and $t$ the time independent variable. $\gamma$ is a morphological (downslope) diffusion coefficient. $q^{\prime}$ is the perturbed net cross-shore component of the sediment flux; here we consider arbitrary angle of wave incidence. Thus, $q^{\prime}$ is the difference between the total cross-shore component of the sediment flux $(q)$ calculated with and without nourishment, i.e.,

$$
\begin{aligned}
q^{\prime}= & q\left(E_{w}(x, t), E_{r}(x, t), \theta(x, t), z_{b, 0}(x)+b(x, t)\right) \\
& -q\left(E_{w, 0}(x), E_{r, 0}(x), \theta_{0}(x), z_{b, 0}(x)\right)
\end{aligned}
$$




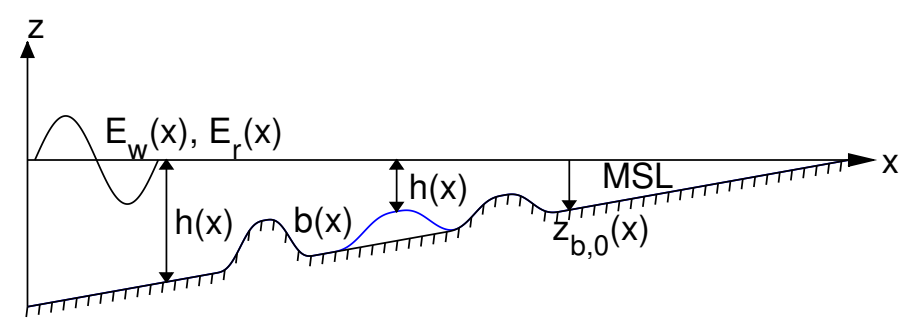

Figure 1: Geometry and coordinate system, where symbol MSL indicates mean sea level.

where subscript, 0 refers to the un-nourished sea bed. The nourishment evolution is therefore purely cross-shore.

The perturbed sediment flux in (2) is therefore the difference between the fluxes that would result from two separate cross-shore simulations, one of the un-nourished cross-shore profile plus nourishment, and the other of the unnourished profile only. Here, however, we assume that the un-nourished profile remains unchanged, either because it is a true equilibrium profile, or because it is evolving more slowly than the nourishment.

In (2) $E_{w}$ is the wave energy density, $E_{r}$ is the wave roller energy density, $\theta$ is the local wave angle of incidence relative to the shore normal, and $z_{b}=z_{b, 0}+b$ is the total sea bed level: existing (un-nourished) profile $\left(z_{b, 0}\right)$ plus nourishment (b). Note that although mean water depth $h(x, t)$ does not appear explicitly in Eq. (2), $h \equiv-z_{b}$ because the perturbation in bed level (b) accounts for changes in depth, and we neglect wave set-up. Because our nourishment is on the shoreface, we expect set-up to be less important. We also neglect mean crossshore tidal current. Throughout we take $\gamma=3.5 \times 10^{-4} \mathrm{~m}^{2} \mathrm{~s}^{-1}$, which is the same as that used in Chen and Dodd (2019); Larson and Hanson (2015). We adopt this simple diffusion model because we seek only to include this physical process at a realistic magnitude. Therefore, we do not pursue a more sophisticated representation.

The study geometry is encapsulated in Fig. 1, in which the background profile (in black), including any bars in that profile, is assumed not to evolve.

In the following we decompose $q$, the total net cross-shore sediment transport, into components from wave skewness, wave asymmetry, and a mean component:

$$
q=q_{s k}+q_{a s}+q_{c}
$$




\subsubsection{Velocity skewness, and asymmetry (acceleration skewness)}

As waves shoal, their shape changes from sinusoidal to an increasingly skewed shape (long trough and more confined, exaggerated crest). After breaking, this shape progressively changes to become highly asymmetrical, i.e., pitched forward. Both skewness and asymmetry are thought to promote significant net onshore sediment transport, and so are considered here, and therefore are included in $q$ and therefore $q^{\prime}$. The skewness of wave velocity $\left(S_{v e l}\right)$ and acceleration $\left(S_{a c c}\right)$ are introduced to describe these changes; these are defined as:

$$
S_{v e l}=\frac{<u^{3}>}{\sigma^{3}(u)}, S_{a c c}=\frac{<a^{3}>}{\sigma^{3}(a)} .
$$

$u$ denotes the intra-wave velocity; here the parameterized expression proposed by Ruessink et al. (2012) is used. $<$. $>$ refers to a time average over the wave period $(T) . \quad a=\frac{\partial u}{\partial t}$ is the wave acceleration. $\sigma($.$) is the standard deviation$ of the variable. Semi-analytical expressions of $S_{v e l}, S_{a c c}, \sigma(u)$ and $\sigma(a)$ are developed and presented in Chen and Dodd (2019), and they are used herein.

\subsubsection{Sediment transport components}

The net sediment transport due to the wave skewness and the wave asymmetry are given by

$$
q_{s k}=K_{s} S_{v e l} \sigma^{3}(u) \cos \theta, q_{a s}=K_{a} S_{a c c} \sigma(a) \cos \theta,
$$

where $q_{s k}\left(q_{a s}\right)$ is the cross-shore component due to wave skewness (asymmetry). The mean current $\left(u_{c}\right)$ driven cross-shore sediment flux component is given by the expression of Soulsby (1997)

$$
q_{c}=A_{s b} u_{c} \cos \theta\left[\left(\left|u_{c}\right|^{2}+\frac{0.018}{C_{D}} u_{w}^{2}\right)^{1 / 2}-u_{c r}\right]^{2.4} .
$$

$u_{w}=\frac{H}{2} \frac{g k}{\omega} \frac{\cosh k z_{0}}{\cosh k h}$ is the wave orbital velocity at the boundary layer edge $z_{0}$ $(0.01 \mathrm{~m}), k$ is the linear wave number, $\omega=\frac{2 \pi}{T}$ is the wave radial frequency, $g=$ $9.81 \mathrm{~m} / \mathrm{s}^{2}$ is the gravitational acceleration, and $H$ is wave height. $C_{D}=0.005$ is the drag coefficient due to current alone. $u_{c r}$ is the threshold current velocity; here we follow e.g. Roos et al. (2004) in setting $u_{c r}=0$, because we wish to study nourishment dynamics. The coefficients, i.e., $K_{s}, K_{a}$ and $A_{s b}$ are the same as in Chen and Dodd (2019). $u_{c} \cos \theta$, the cross-shore component of the mean current, contains two components: near-bed flow derived by consideration of 
mass balance, and near-bed mean flow due to streaming. These are considered separately in $\S 2.3$.

\subsection{Wave energy balance}

In the present study we consider both shoaling and refraction. Accordingly, the wave energy density $\left(E_{w}=\frac{1}{8} \rho g H_{r m s}^{2}\right)$ balance in the cross-shore is:

$$
\frac{\partial\left(E_{w} c_{g} \cos \theta\right)}{\partial x}=-\mathcal{D}_{w}
$$

$\rho=1027 \mathrm{~kg} / \mathrm{m}^{3}$ is the water density, $H_{r m s}$ the root mean square wave height, and $c_{g}$ is the group velocity from linear wave theory with representative wave period T. Snell's law is used to determine $\theta(x)$ (Dean and Dalrymple, 1991). Here, we use the energy dissipation expression $\mathcal{D}_{w}$, of Baldock et al. (1998). This is

$$
\mathcal{D}_{w}=\frac{\rho g \omega}{8 \pi} \exp \left[-\left(\frac{H_{b}}{H_{r m s}}\right)^{2}\right]\left(H_{b}^{2}+H_{r m s}^{2}\right),
$$

$H_{b}$ is the breaker height, and is given by (Battjes and Janssen, 1978),

$$
H_{b}=\frac{0.88}{k} \tanh \left(\frac{\gamma_{b}}{0.88} k h\right) .
$$

and where $\gamma_{b}$ is the breaker coefficient, where (Ruessink et al. 2003)

$$
\gamma_{b}=0.76 k h+0.29
$$

By using this expression instead of that of Van Leeuwen et al. (2006) we lose the convenience of shifting between random and monochromatic waves. On the other hand, we gain the advantage of an expression that has been validated under field conditions. The roller energy $\left(E_{r}\right)$ equation is also extended to consider refraction:

$$
\frac{\partial\left(E_{r} c \cos \theta\right)}{\partial x}=\mathcal{D}_{w}-\mathcal{D}_{r}
$$

where, $c=\frac{\omega}{k}$ is the phase velocity. The expression for roller energy dissipation $\left(\mathcal{D}_{r}\right)$ is given in Chen and Dodd (2019).

\subsection{Mean current}

If we consider mean current to be that that is time invariant at the timescale of the surface gravity waves, then it has three main cross-shore contributions here: tidal current, return flow (undertow) and streaming. We neglect the tidal 
current, but make adjustments for tide through changes in free surface elevation.

Chen and Dodd (2019) considered return flow only. Here we both improve the return flow description and introduce streaming into our sediment dynamics.

\subsubsection{Streaming}

The horizontal non-uniformity of the wave velocity field generates a mean bottom boundary layer current (streaming) in the direction of wave propagation (Longuet-Higgins, 1953). Streaming is thought to contribute primarily to mean onshore sediment transport (Roelvink and Reniers, 2011). LonguetHiggins (1957) found that at the top of the boundary layer the induced wave averaged streaming velocity is

$$
u_{s t r}=\frac{3}{16 c}\left(\frac{\omega H_{r m s}}{\tanh (k h)}\right)^{2} .
$$

We make use of this equation herein.

\subsubsection{Mean current based on mass conservation}

Consideration of conservation of mean wave-induced mass flux over the water column leads to a mean return flow to balance the onshore net mass flux due to Stokes drift and roller $($ Svendsen, 2006). Chen and Dodd $(2019)$ considered a depth-invariant mean return flow to balance the onshore flux. This leads to a probable overestimation of near-bed offshore-directed sediment flux in the offshore region. Here we make use of the method proposed by Roelvink and Reniers (2011), which is based on a so-called generalized Lagrangian mean approach, to calculate the return flow. This method is shown to give good results both inside and outside of the surf zone. In this approach, the mean current $u_{L}(z), z$ being the vertical coordinate (positive upward), is allowed to have a vertical profile,

$$
u_{L}(z)=u_{E}(z)+u_{\text {stokes }}(z)
$$

Here, $u_{E}(z)$ is the Eulerian velocity with a logarithmic vertical profile driven by surface and bottom shear stress, and $u_{\text {stokes }}(z)$ describes the vertical distribution of stokes drift (Phillips, 1977)

$$
u_{\text {stokes }}=\frac{1}{8}\left(k H_{r m s}\right)^{2} c \frac{\cosh (2 k(z+h))}{\sinh ^{2}(k h)} \cos \theta .
$$

A detailed description of $u_{L}(z)$ is given in Appendix A. 


\subsection{Total sediment flux}

We combine expressions for streaming and mass-conservation-induced flow to get

$$
u_{c} \cos \theta=\left.u_{L}\right|_{z=-h+0.1 \mathrm{~m}}+u_{\text {str }} \cos \theta f_{\text {damp }},
$$

which thus consists of a near bottom wave current evaluated mean flow $0.1 \mathrm{~m}$ above the sea bed from Eq. [13), and streaming in the onshore direction. Note that a damping factor $f_{d a m p}=\exp \left(-D_{w} / 3.0\right)$ is included which diminishes the effect of streaming in the case of breaking waves. This is because the effect of streaming is only relevant for non-breaking waves (Roelvink and Reniers, 2011, Kranenburg et al. 2012).

The total net cross-shore sediment transport is therefore the summation of the net sediment flux due to wave skewness, wave asymmetry and mean current:

$$
q=q_{s k}+q_{a s}+q_{c}=q_{s k}+q_{a s}+q_{L}+q_{s t r}
$$

Note that $q_{L}$ and $q_{s t r}$ cannot be fully decoupled in Eq. (6); hereafter we refer to $q_{c}$ only, rather than $q_{L}$ and $q_{s t r}$.

\section{Nourishment kinematics}

An analysis of the propagation of a small amplitude perturbation (nourishment) via Eq. (2) yields (neglecting the diffusion term, Chen and Dodd, 2019)

$$
\frac{\partial b}{\partial t}+\frac{1}{1-p} \frac{\partial q^{\prime}}{\partial b} \frac{\partial b}{\partial x}=-\frac{1}{1-p}\left\{\frac{\partial q^{\prime}}{\partial E_{w}^{\prime}} \frac{\partial E_{w}^{\prime}}{\partial x}+\frac{\partial q^{\prime}}{\partial E_{r}^{\prime}} \frac{\partial E_{r}^{\prime}}{\partial x}+\frac{\partial q^{\prime}}{\partial \theta^{\prime}} \frac{\partial \theta^{\prime}}{\partial x}\right\}
$$

Therefore

$$
c_{n}=\frac{1}{1-p} \frac{\partial q^{\prime}}{\partial b}=-\frac{1}{1-p}\left\{\frac{\partial q_{s k}}{\partial h}+\frac{\partial q_{a s}}{\partial h}+\frac{\partial q_{c}}{\partial h}\right\}
$$

where $c_{n}$ is the intrinsic propagation speed of the perturbation.

In Fig. 2(a) we plot $c_{n}$ as a function of cross-shore position on a plane beach (slope 0.01) and offshore wave height. It can be seen that for small wave heights and larger depths we always have positive $c_{n}$, indicating onshore propagation of any small morphological perturbation as long as the forcing terms on the right of Eq. (17) are negligible. These forcing terms are likely to be small prior to breaking, but if we ignore the forcing terms for all depths and focus just on the free kinematics shown in Fig. 2(a), we see that, starting from offshore (extreme left), $c_{n}$ becomes more positive as the waves shoal. This effect is partly 
attributable to streaming, as can be seen by comparing Fig. 2(a) with 2(b), in which streaming is omitted. The rest is primarily due to skewness. Comparing Fig. 2(b) and Fig. 2(c) (the equivalent plot from Chen and Dodd, 2019), we see that the more accurate description of return flow implemented here is crucial to capture this behaviour. In the region of significant wave breaking the free kinematics are such that $c_{n}<0$, indicating offshore propagation. Therefore, a point of convergence is likely to exist for $c_{n} \approx 0$; this point is located progressively further offshore with increasing wave height. $c_{n}$ reaches a maximum of about $1.7 \times 10^{-4} \mathrm{~m} / \mathrm{s}(14.6 \mathrm{~m} /$ day $)$.

Onshore propagation of a perturbation is not synonymous with onshore sediment movement, so positive $c_{n}$ does not imply onshore movement of the sediment in a nourishment: the feeder effect (although it is likely to be at least partially true because the nourishment must be composed of some sediment to exist and propagate onshore). Regardless, the onshore propagation of the perturbation (the shape) will result in the lee effect, in which waves dissipate their energy on the nourishment as it propagates into shallower water.

\section{Terschelling nourishment}

\subsection{Study area and data}

Terschelling is one of the chain of barrier islands along the northern Dutch coast that separate the North Sea from the Wadden Sea (Fig. 3). The median grain size $\left(D_{50}\right)$ varies from $150 \mu \mathrm{m}$ to $220 \mu \mathrm{m}$ (the sediment is coarser shoreward). To protect Terschelling from erosion, a total amount of $2.1 \mathrm{Mm}^{3}$ $\left(D_{50}=200 \mu \mathrm{m}\right)$ of sand was placed in the shoreface of Terschelling island from May to October 1993 (Hoekstra et al. 1994, NOURTEC project). The nourishment was placed in depths of $5-7 \mathrm{~m}$, and has a longshore extent of about $4.5 \mathrm{~km}$ (see black block denoted as 'nourishment area' in Fig. 33). Because our model is 1D (on/offshore) we are interested in the cross-shore movement of the nourishment. The elongated, quasi-shore-parallel geometry of the Terschelling nourishment therefore offers an opportunity to apply the model where we may expect it to describe the dominant dynamics. Although monitoring continued for a number of years, we focus on the first six months for our simulation, because this means that we are within initial cross-shore adjustment region of the observed nourishment. This timescale is also short enough to limit the influence of the rhythmic bar system at the site, and also of alongshore sediment flux divergence, which are thought to contribute significantly over 3-year timescales 
(a)

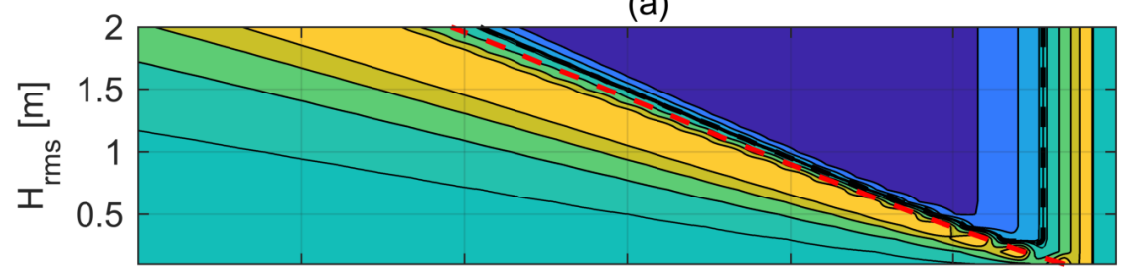

$\times 10^{-4}$

(b)

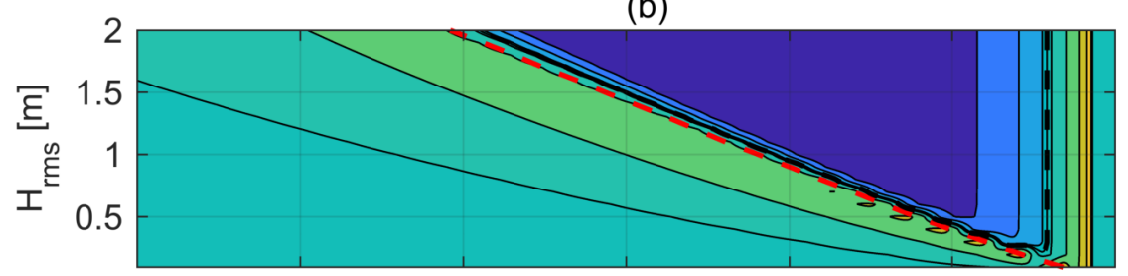

(c)

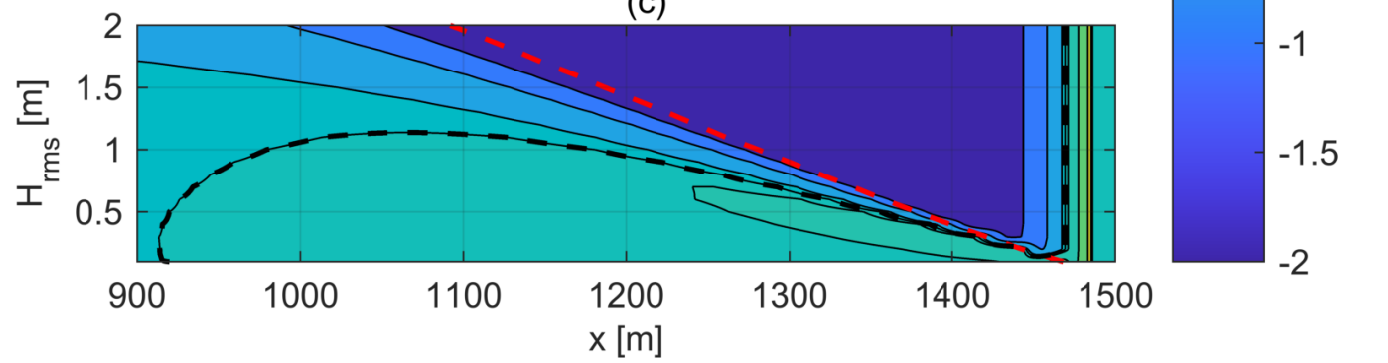

Figure 2: Comparison of intrinsic propagation speed $\left(c_{n}\right.$, in $\left.\mathrm{m} / \mathrm{s}\right)$ calculated with: (a), description of total near bottom wave current $u_{c} \cos \theta$ from Eq. 15); (b), description of return flow $u_{c} \cos \theta$ from Eq. 15 but neglecting the $u_{s t r}$ component; and (c), depth averaged return flow (Eq. (15) in Chen and Dodd (2019)). The plane beach (with slope of 0.01) is forced by normal incident waves (with $T=6 \mathrm{~s}$ ). The dark thick curve highlights the zero contour of $c_{n}$. The thick red curve denotes the cross-shore position of the break point, identified here as the position of maximum wave height.

to onshore sediment movement (Grunnet and Ruessink, 2005). We discuss limitations in the Discussion section. Therefore, the central transect denoted by the shore normal black line in Fig. 3 is chosen. This transect is known as transect 17.000 in Grunnet and Ruessink (2005).

The sea bed profile of the study transect was measured both before and after the nourishment, see Fig. 4. The nourishment mostly filled in the trough between middle and outer bars. Most morphological change took place in this first six months after the nourishment (Grunnet et al., 2004). 


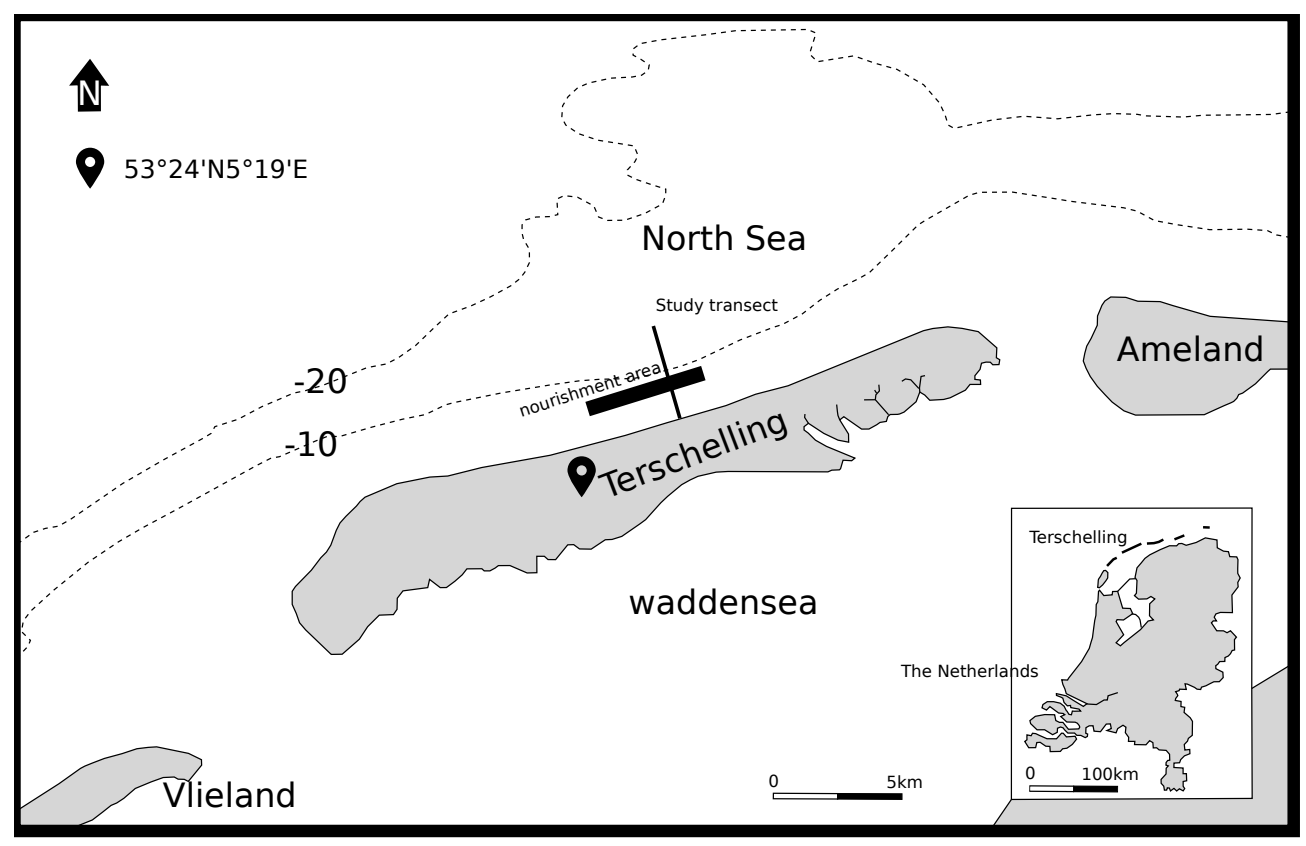

Figure 3: Location and study area. The transect denoted by the black solid line normal to the coast is the study transect. The figure is reproduced from Figure 1 in Grunnet et al. (2004).

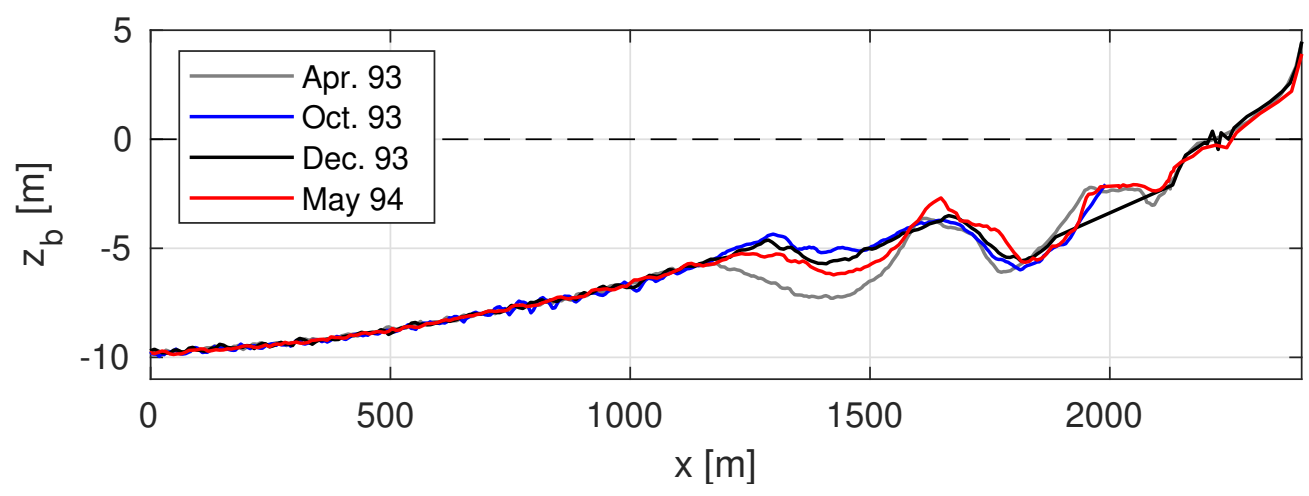

Figure 4: Measured cross-shore sea bed profiles of study transect. 
(a)

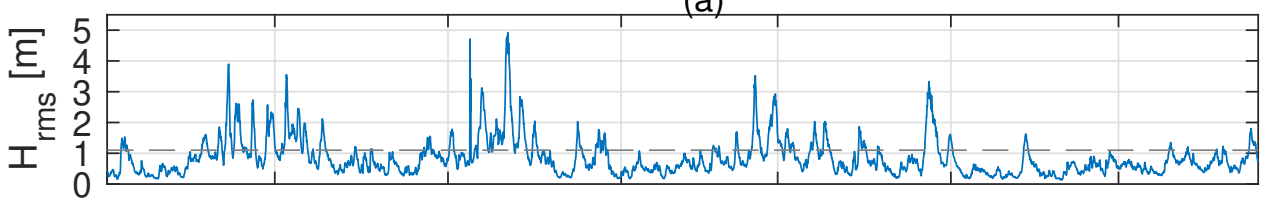

(b)
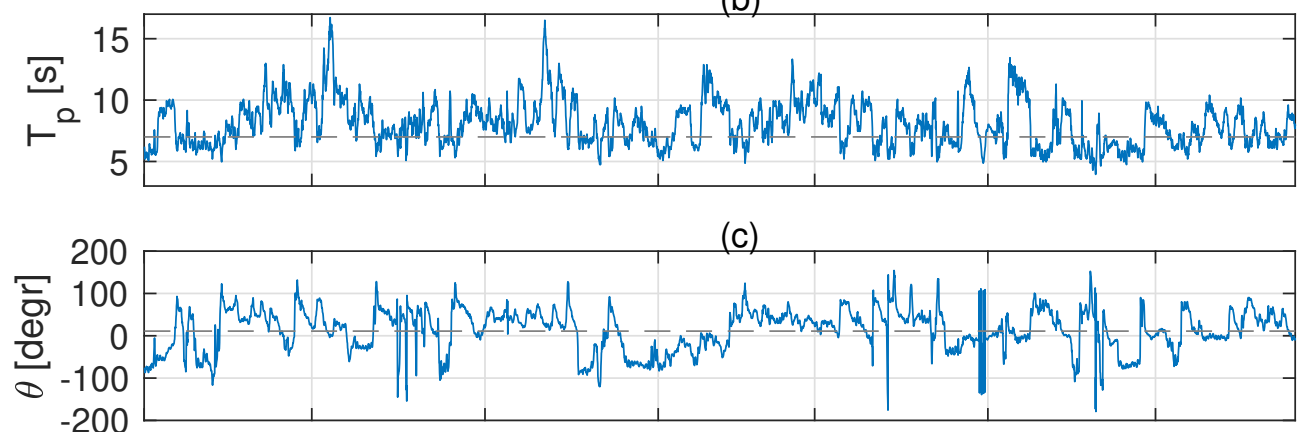

(d)

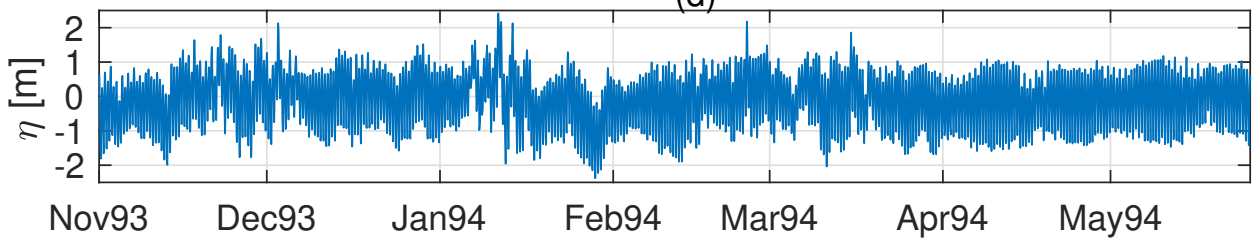

Figure 5: Hydrodynamic conditions observed at $-15 \mathrm{~m}$ offshore, showing: (a), offshore wave height $H_{r m s}$; (b), wave period $T$; (c), wave incident angle $\theta$ (with respect to shore normal direction, negative value is measured in a clockwise direction); and (d), tide mean water level $\eta$. The grey horizontal dashed lines highlight the prevailing wave conditions observed at the site.

The hydrodynamic conditions from Nov 93 to May 94 are shown in Fig. 5 (recorded at hourly intervals). As mentioned, tide is here accounted for by shifting the water surface. Also, offshore directed waves (i.e., $|\theta|>90^{\circ}$ ) are not included in this study.

\subsection{Numerical considerations}

A uniform grid spacing $\Delta x=1 \mathrm{~m}$ in the cross-shore $x$ direction is used. This was found to achieve convergence both hydrodynamically (convergence test for hydrodynamics only), and morphodynamically (convergence test for bed level). A so-called Euler-Heun method (Süli and Mayers, 2003), i.e., a predictor and corrector algorithm, is applied to update the nourishment Eq. (1). A $30 \mathrm{~s}$ morphodynamic time step is chosen which is the largest value that achieved 


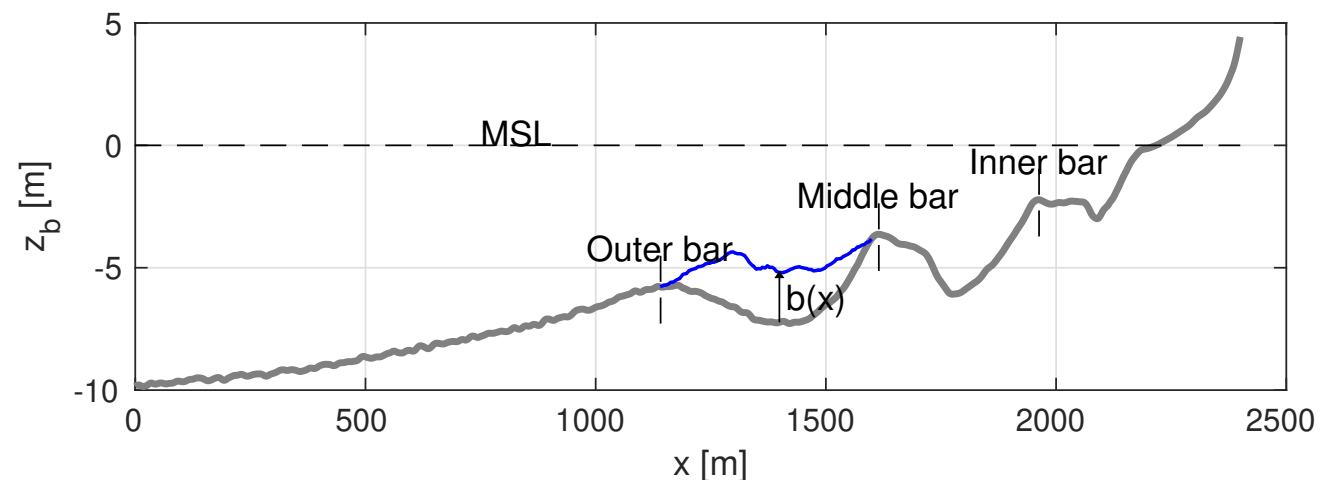

Figure 6: Sea bed profile showing basic profile (grey thick line) and nourishment (blue thin line).

convergence in bed evolution. The profile of April 1993 (see Fig. 4) was measured right before the implementation of the nourishment. We therefore take this unnourished profile as the basic profile of our study, perturbations from which are described by Eq. (1): see Fig. 6, in which the initial nourishment $(b(x, t=0))$ is the blue line. The pre-nourishment profile has three sandbars, referred to as the outer bar, middle bar and inner bar. Thus, $b(x, t=0)$ is the sand placed in the trough between outer and middle bar (from $x=1140$ to $x=1600 \mathrm{~m}$ ).

\subsection{Terschelling Nourishment kinematics}

In Fig. 7 we again plot the intrinsic small amplitude nourishment propagation speed $\left(c_{n}\right)$ at Terschelling for prevailing wave direction $\left(\theta=11^{\circ}\right)$ and period $(T=7 \mathrm{~s})$. The picture is reminiscent of that in Fig. 2, except that the effect of the bars is apparent. These both cause breaking and restrict it to their vicinity, so we do not see the point of convergence moving offshore. As wave height increases, $c_{n}$ becomes negative on the bars. This picture implies that a nourishment placed in between a pair of bars will stay there. This conclusion must be qualified by noting that it does not consider the forcing terms in Eq. (17) and only small amplitude perturbations. In the next section we look at the full, finite-amplitude dynamics. The other thing to note is that $c_{n}$ is about an order of magnitude smaller than that in Fig. 2, with the maximum value $\approx 2.5 \times 10^{-5} \mathrm{~m} / \mathrm{s} \approx 2.16 \mathrm{~m} /$ day. 


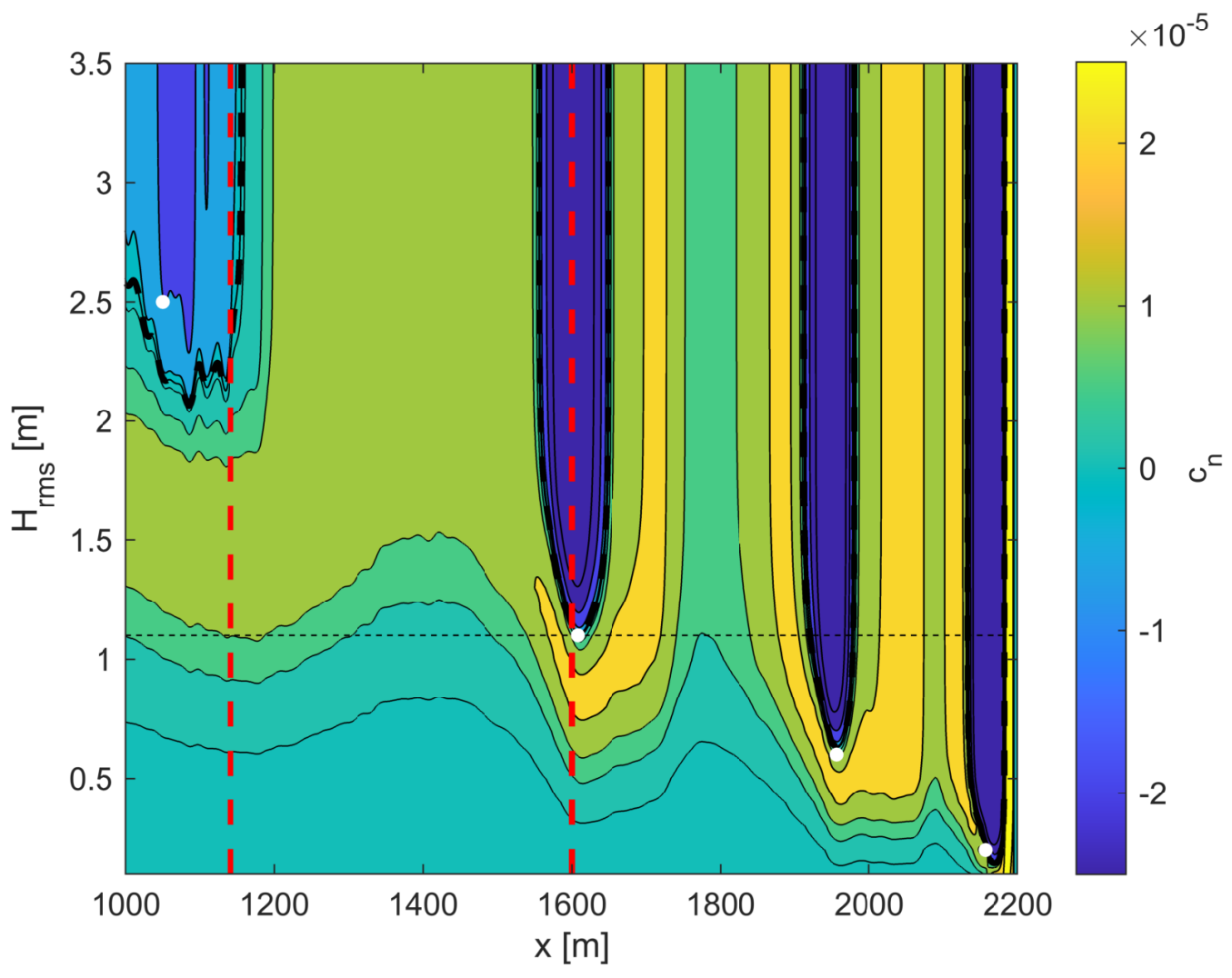

Figure 7: Sensitivity of $c_{n}$ (in $\mathrm{m} / \mathrm{s}$ ) to offshore wave height for the Terschelling site (prenourishment). Wave period and incident angle are kept as $7 \mathrm{~s}$ and $11^{\circ}$, respectively. A positive (negative) $c_{n}$ indicates onshore (offshore) propagation of the nourishment. Zero contour of $c_{n}$ is highlighted by thick black dashed line. The representative wave condition used in section 4.4 is indicated with horizontal dashed line. White dots denote the location of break points and vertical red dashed lines indicate the shoreward and seaward end of nourishment. 


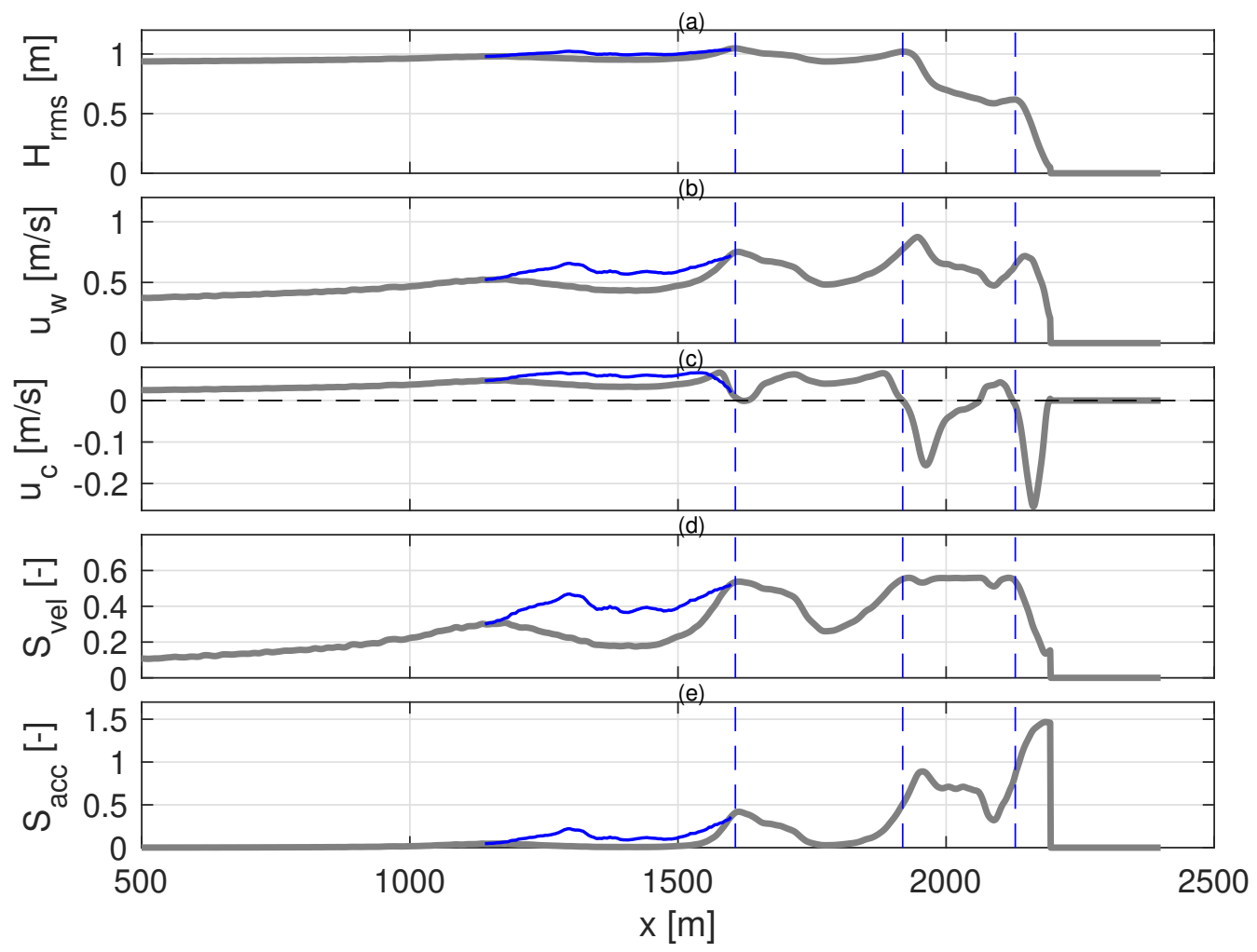

Figure 8: Cross-shore hydrodynamics: (a) $H_{r m s}$, (b) $u_{w}$, (c) $u_{c}$, (d) $S_{v e l}$ and (e) $S_{a c c}$. Waves of representative value is imposed, i.e., $H_{r m s}=1.1 \mathrm{~m}, T=7 \mathrm{~s}$ and $\theta=11^{\circ}$. Thick grey curves refer to hydrodynamics for the basic profile and the thin blue curves refer to that with nourished sea bed. Three vertical blue dashed lines denote the location of break points.

\subsection{Effect of the finite-amplitude nourishment}

We examine the effect of the Terschelling nourishment under moderate wave conditions: $H_{r m s}=1.1 \mathrm{~m}, T=7 \mathrm{~s}$ and $\theta=11^{\circ}$ (Grunnet et al. 2005). These wave heights represent those in between those of the storm events and the beach recovery (low wave height) durations; the period and angle of incidence are annual average values. The water level is set to be at mean tide $(\eta=0 \mathrm{~m})$.

The basic profile (grey line in Fig. 8 ) shows the waves beginning to break on the middle bar $(x=1608 \mathrm{~m})$, and then more pronounced breaking on the inner bar, and again near the shore (Fig. 8 (a)). The nourishment induces some shoaling. The background $u_{c}$ is onshore directed except when the waves are breaking. $S_{v e l}$ and $S_{a c c}$ behave as expected: skewness increases as the waves shoal on the bar, and decreases as they deshoal in the trough, and finally dimin- 


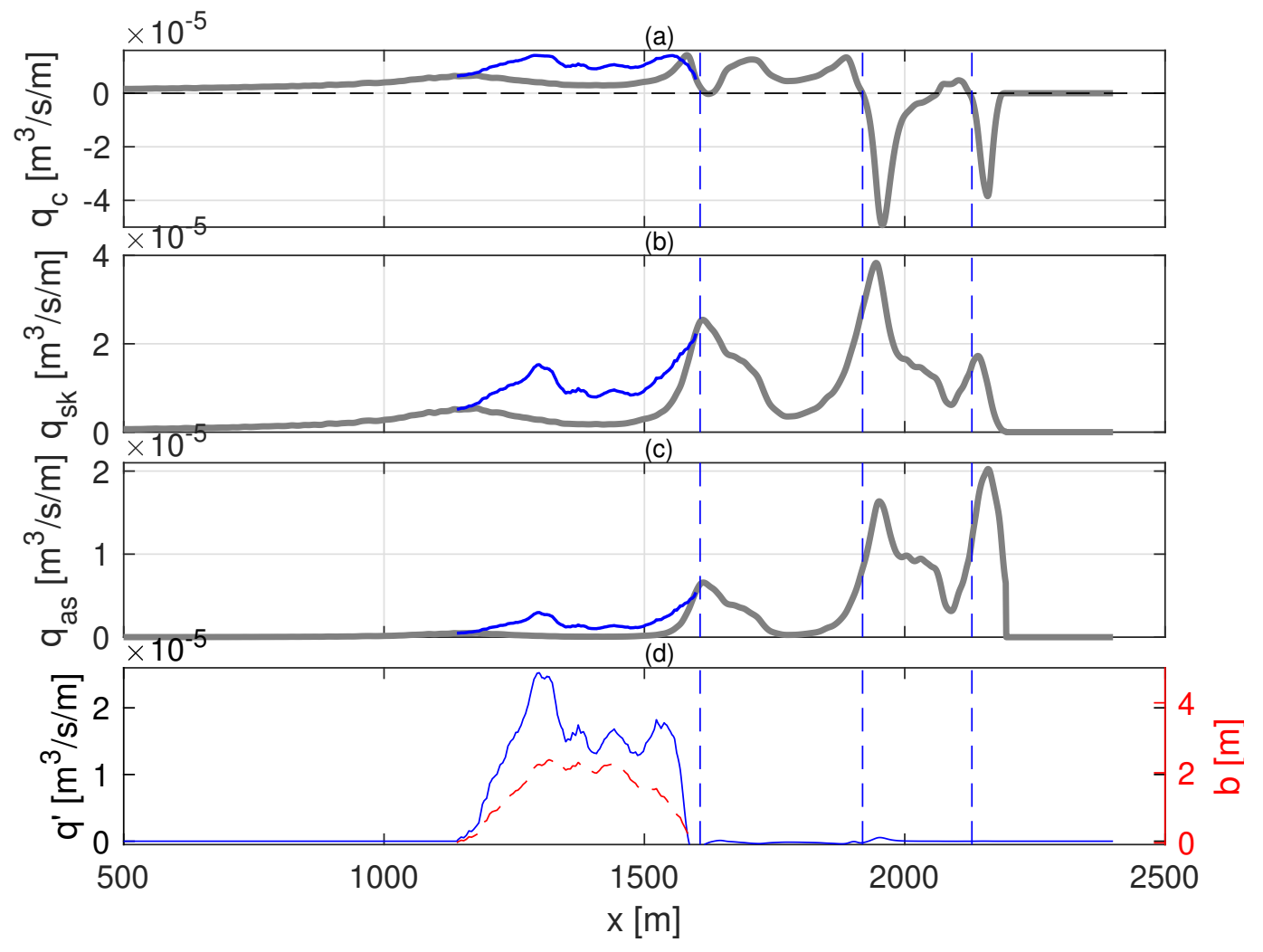

Figure 9: Sediment flux of: (a), current-driven component $q_{c}$; (b), wave-skewness-driven component $q_{s k}$; (c), wave-asymmetry-driven component $q_{a s}$; and (d), total perturbed transport $q^{\prime}$ and (dashed line) $b$. Waves of representative value is imposed. Vertical dashed lines are as in Fig. 8 The thick grey (thin blue) curve represents the fluxes for the basic (nourished) profile.

ishes in very shallow water as the waves become very asymmetrical. As they do so $S_{a c c}$ achieves its maximum. The effect of the nourishment is to increase $u_{c}, S_{v e l}$ and $S_{a c c}$, due to extra shoaling (Fig. 8 (c-e)). The increase in $u_{c}$ is due to an increase in both streaming velocity and near bottom wave current, both induced by the nourishment.

The consequence of the hydrodynamic changes in Fig. 8 can be seen on sediment fluxes in Fig. 9. Because $S_{v e l}, S_{a c c}$ and $u_{c}$ all increase due to the nourishment, $q_{s k}, q_{a s}$ and $q_{c}$ increase (via Eq. (5) and Eq. (6)). Consequently, the nourishment induces an increase in all the sediment fluxes (see blue curves in Fig. 91, leading to an overall onshore (positive) sediment flux perturbation, $q^{\prime}$, (see Fig. 9(d)), thus implying that placement of the nourishment increases 
onshore supply of sediment at that location. The divergence of the positive $q^{\prime}$ will, overall, also lead to onshore propagation of the nourishment, because both $b$ and $q^{\prime}$ are positive, with peaks roughly coinciding (see Fig. 9. d); also see Chen and Dodd (2019)).

In the next three subsections we examine the sensitivity of the perturbed sediment flux, $q^{\prime}$, to variations in hydrodynamic parameters, keeping other hydrodynamic parameters fixed. These parameter values can be interpreted as those that established the non-evolving background profile, or as different values, but with the background profile evolving more slowly such that it can be considered invariant. In either case the resulting pattern in $q^{\prime}$ shows how the nourishment would start to evolve. The actual nourishment evolution is considered later.

\subsubsection{Sensitivity to wave height}

We now consider the effect of differing wave height, keeping $T$ and $\theta$ fixed. In Fig. 10 we show this in terms of perturbations in sediment transport rate induced by the nourishment: $q_{c}^{\prime}$ (mean), $q_{s k}^{\prime}$ (skewness driven), $q_{a s}^{\prime}$ (asymmetry driven), and total $q^{\prime}$. To help illustrate the effect we also indicate on Fig. 10 three wave heights that we characterise as mild $\left(H_{r m s}=0.5 \mathrm{~m}\right)$, moderate (as before), and stormy wave heights $\left(H_{r m s}=2.5 \mathrm{~m}\right)$. In Fig. 10(d) we can see that for mild and moderate wave heights the nourishment causes a positive $q^{\prime}$, and thus feeds the beach. This positive perturbation is primarily due to mean current and skewness. In contrast, for stormy waves we see a negative $q^{\prime}$, primarily $q_{c}$, which thus transports sediment offshore. All three mechanisms (Fig. 10(a-c)) provide positive perturbations for mild and moderate conditions; for stormy waves $q^{\prime}$ reverses due to these bigger waves breaking on the nourishment. Under these latter conditions note the area immediately shoreward of nourishment. Here $q^{\prime}>0$ again, because the breaking occurring on the nourishment now no longer happens further shoreward. Therefore, the middle bar is now, relatively speaking, feeding the beach. This effect is in addition to the lee effect of the nourishment (i.e. pure reduction in wave heights shoreward). The cross-shore $q^{\prime}$ profile for mild and moderate wave heights is consistent with an onshore migration of the nourishment. The positive-negative-positive profile for stormy waves (initially positive on the extreme seaward side, where skewness out-competes mean current) leads to a generally offshore propagation. 


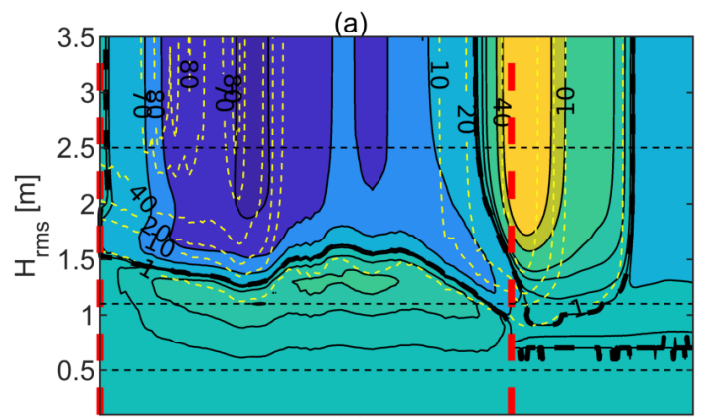

(c)

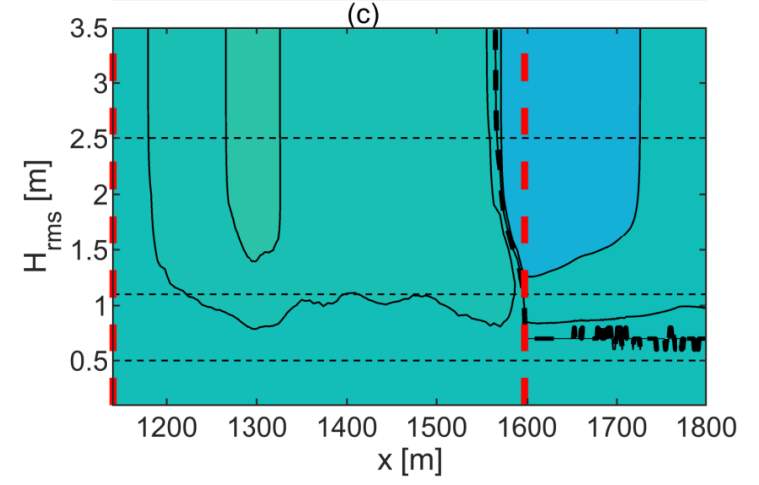

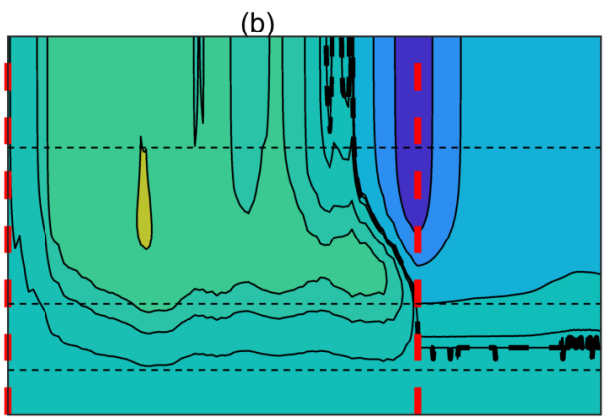

(d)

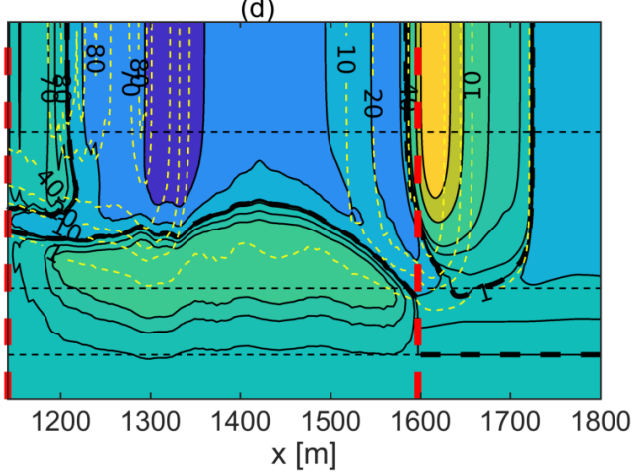

2
6

$\times 10^{-5}$

Figure 10: Sensitivity of perturbed sediment flux to offshore waves height at mean tide $(\eta=0$ $\mathrm{m}$ ), showing: (a), current driven sediment flux perturbation $\left(q_{c}^{\prime}\right) ;(\mathrm{b})$, wave skewness driven sediment flux perturbation $\left(q_{s k}^{\prime}\right)$; (c), wave asymmetry driven sediment flux perturbation $\left(q_{a s}^{\prime}\right)$; and (d), total perturbation $q^{\prime}$. The wave period and incident angle are $T=7 \mathrm{~s}$ and $\theta=11^{\circ}$. The zero contour line is highlighted with the black dashed line. The yellow contour lines show the wave energy dissipation $\left(\mathcal{D}_{w}\right)$. The red vertical dashed lines indicate the shoreward and seaward end of initial nourishment. The horizontal dashed lines refer to mild $\left(H_{r m s}=0.5 \mathrm{~m}\right)$, moderate $\left(H_{r m s}=1.1 \mathrm{~m}\right)$ and stormy wave heights $\left(H_{r m s}=2.5 \mathrm{~m}\right)$. 

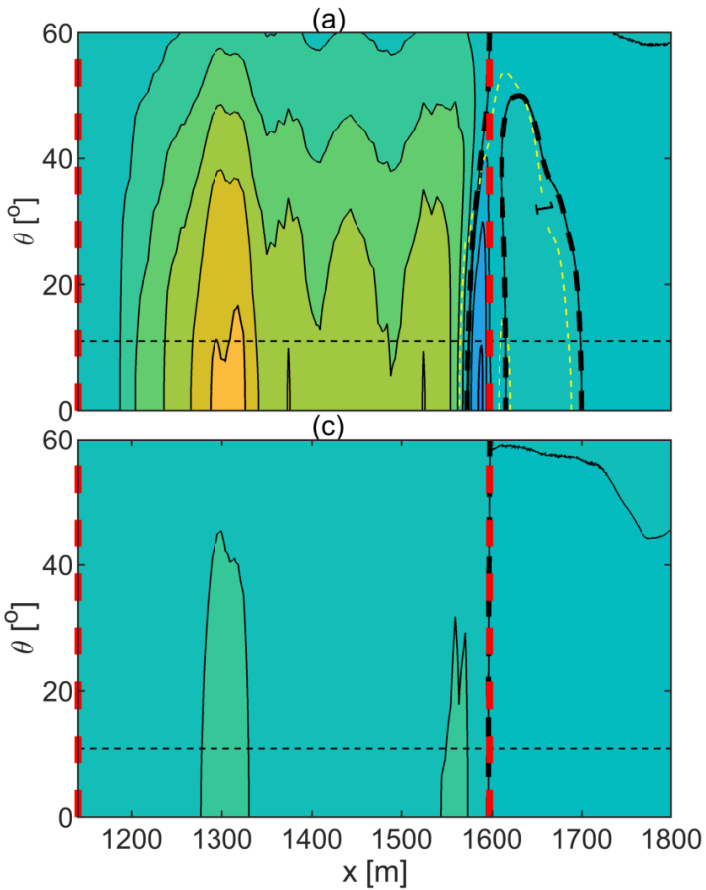

(b)

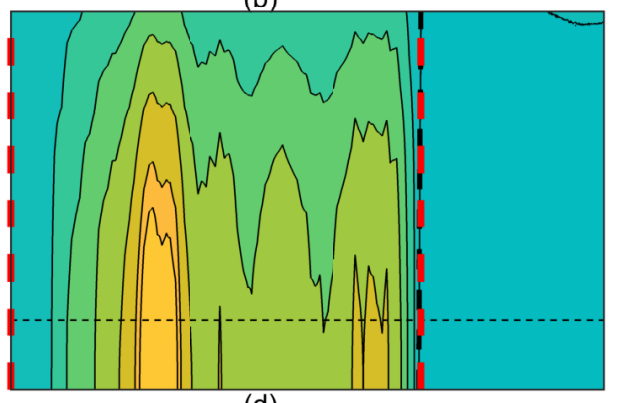

(d)

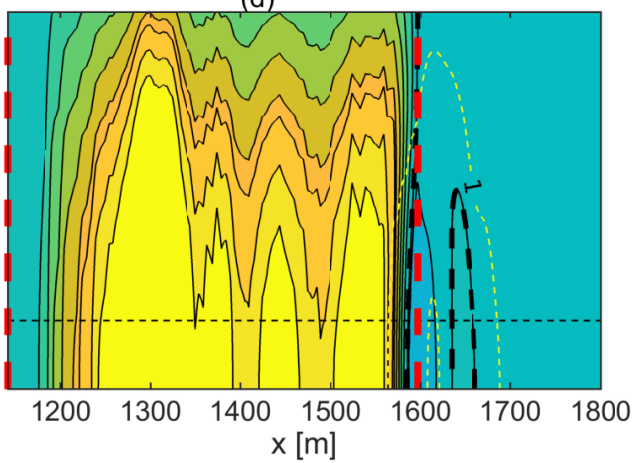

$-1.5$

$-0.5$

0

$\mathrm{q}^{\prime}\left[\mathrm{m}^{3} / \mathrm{s} / \mathrm{m}\right]$

0.5

1

1.5

$10^{-5}$

Figure 11: Sensitivity of perturbed sediment flux to offshore wave incidence angle at mean tide $(\eta=0 \mathrm{~m})$, showing: (a), $q_{c}^{\prime} ;(\mathrm{b}), q_{s k}^{\prime} ;(\mathrm{c}), q_{a s}^{\prime}$; and (d), $q^{\prime}$. The wave period and incident angle are $H_{r m s}=1.1 \mathrm{~m}$ and $T=7 \mathrm{~s}$. The zero contour line is highlighted with the thick black dashed line. The horizontal black dashed line corresponds to the representative wave incidence $\theta=11^{\circ}$. Red vertical dashed lines indicate the start and end position of initial nourishment. The yellow contour lines show the wave energy dissipation $\left(\mathcal{D}_{w}\right)$. 


\subsubsection{Sensitivity to wave incident angle and period}

We now hold $H_{r m s}=1.1 \mathrm{~m}$ constant and vary $\theta$ and then $T$. The effect of $\theta$ on $q^{\prime}$ is presented in Fig. 11. For $\theta=11^{\circ}$ (dashed line in Fig. 11) we see the results corresponding to those for $H_{r m s}=1.1 \mathrm{~m}$ in Fig. 10. Note that the smaller colour bar range reveals the finer detail. As might be expected the effect mainly apparent is a reduction in the positive $q^{\prime}$ for larger angles, due to increased refraction yielding smaller (shoaling) wave heights, and therefore decreased skewness and onshore mean flow.

In Fig. 12 we show the sensitivity to wave period. For $T \approx 9 \mathrm{~s}$ a peak in $q^{\prime}$ can be observed. This is due primarily to the corresponding peak in $q_{s k}^{\prime}$. For this period (for this wave height) the nourishment can therefore be considered optimally active, yielding maximum enhanced onshore sediment movement and a general onshore migration of the nourishment. Note that a corresponding peak can be seen in Fig. 10(d), in which $T$ is fixed and the "optimal" $H_{r m s} \approx 1.4 \mathrm{~m}$. For longer periods asymmetry grows and skewness diminishes, as does mean current, and waves begin to break on the nourishment $(\approx 1300 \mathrm{~m})$, and also on the middle bar $(\approx 1600 \mathrm{~m})$. Therefore, for a broad range of periods and directions at moderate wave heights the nourishment is active and feeding sand onshore.

\subsubsection{Sensitivity to mean water level (tide)}

The evolution of the nourishment is also affected by tide. Here, the effect of tide is accounted for by shifting the water surface (thus changing total water depth). At Terschelling, tides are semi-diurnal and meso-tidal. Tidal ranges are about $1.2 \mathrm{~m}$ (Neap) and $2.8 \mathrm{~m}$ (Spring), respectively.

For $H_{r m s}=1.1 \mathrm{~m}$ the sensitivity of $q^{\prime}$ to tide is shown in Fig. 13 . Onshore sediment flux $\left(q^{\prime}>0\right)$ is induced for a wide range of water levels (Fig. 13. d)). The dominant processes are skewness-driven and mean $q^{\prime}$, which mostly reinforce each other, but which on lower tides are opposed, because of wave breaking on low tides under only moderate wave heights.

\subsection{Nourishment evolution}

Up till now, we have examined the linear kinematics of the Terschelling nourishment (Fig. 7), the perturbed finite amplitude sediment dynamics (Fig. 869), and the sensitivity of those dynamics to the wave and tide conditions (Fig. 10 13). In these we used the initial nourishment (Nov. 1993) to examine its response. We now start from that initial condition, and allow it to evolve over 
(a)
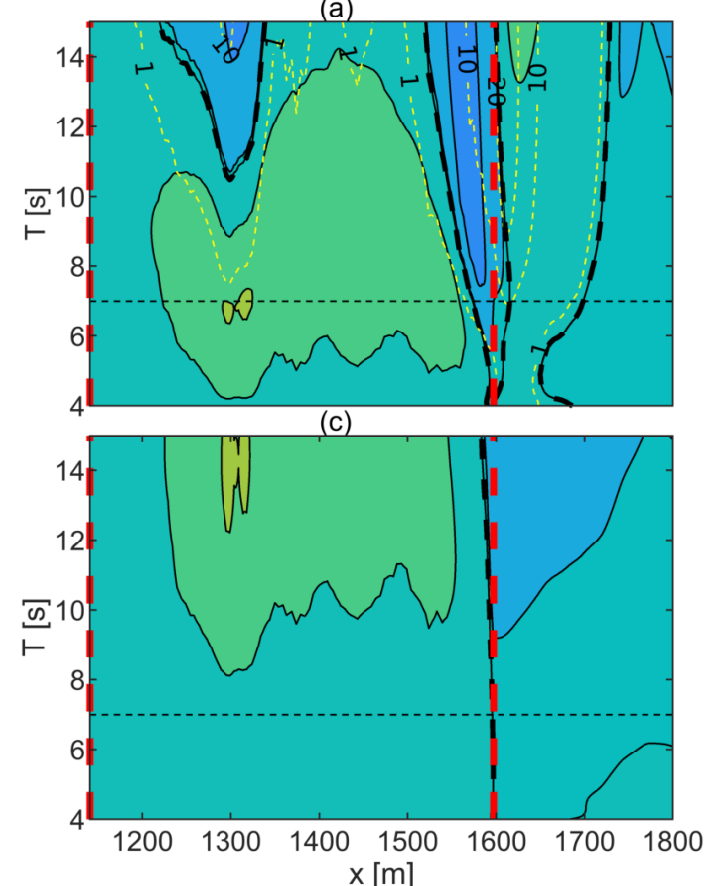

(b)

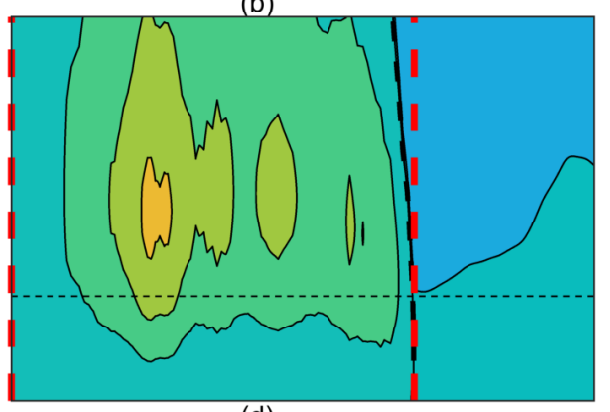

(d)

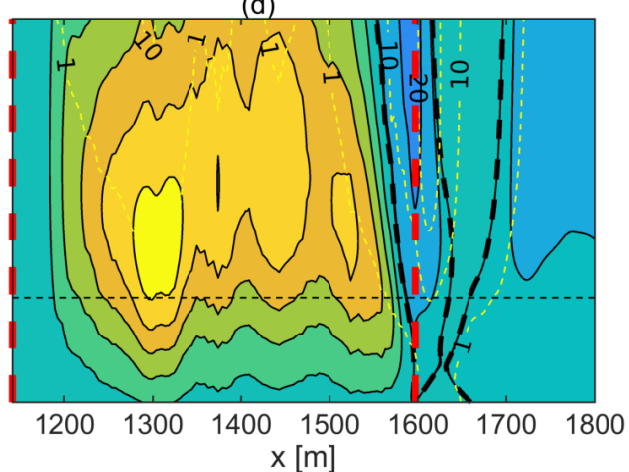

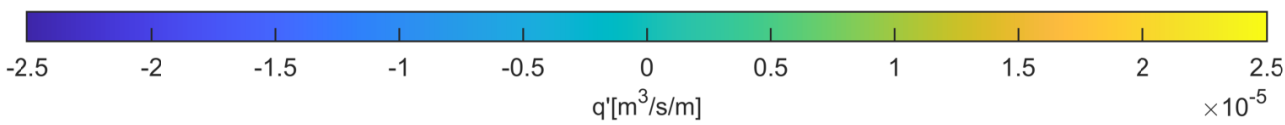

Figure 12: Sensitivity of perturbed sediment flux to wave period at mean tide $(\eta=0 \mathrm{~m})$, showing: (a), $q_{c}^{\prime} ;(\mathrm{b}), q_{s k}^{\prime} ;(\mathrm{c}), q_{a s}^{\prime}$; and (d), $q^{\prime}$. The wave period and incident angle are kept as $H_{r m s}=1.1 \mathrm{~m}$ and $\theta=11^{\circ}$. The zero contour line is highlighted with the thick black dashed line. The horizontal black dashed line corresponds to representative wave period $T=7$ s. Red vertical dashed lines indicate the shoreward and seaward end of initial nourishment. The yellow contour lines show the wave energy dissipation $\left(\mathcal{D}_{w}\right)$. 
(a)

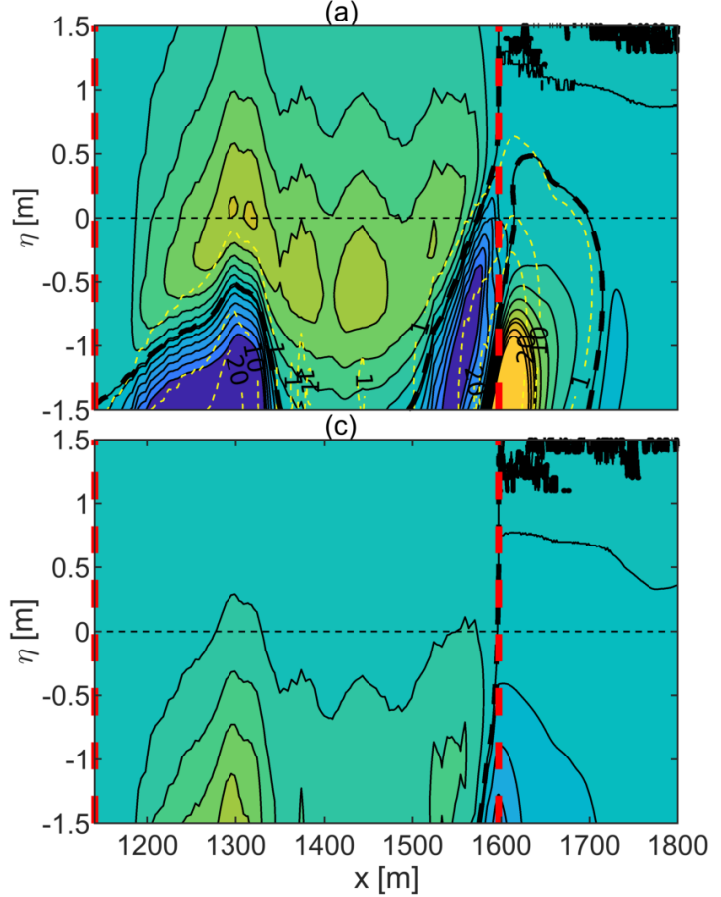

(b)

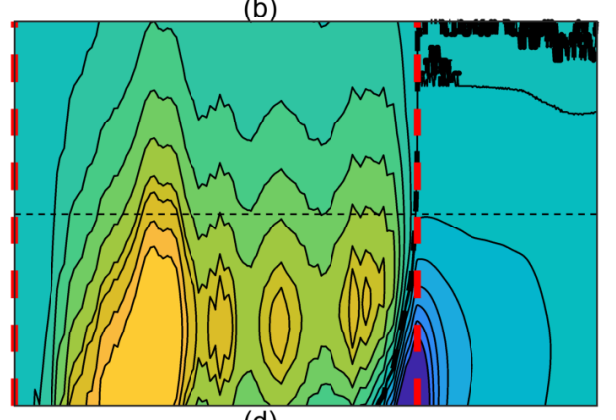

(d)

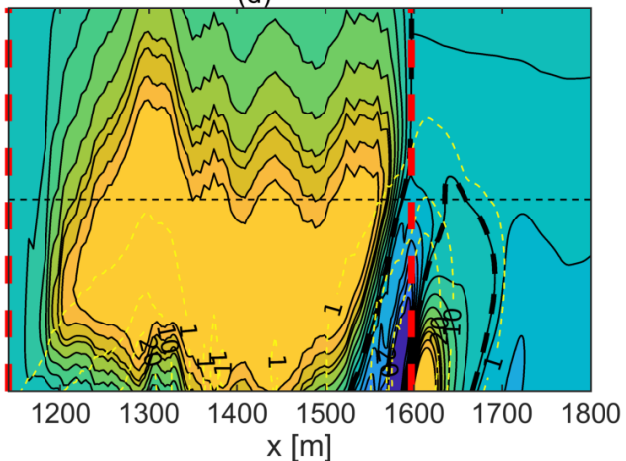

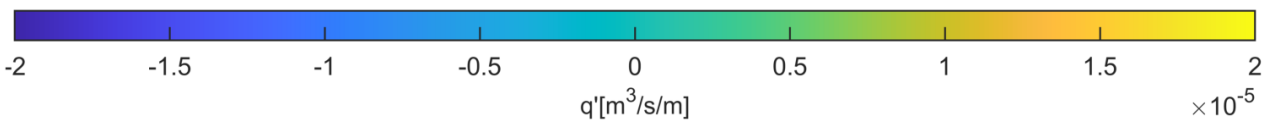

Figure 13: Sensitivity of perturbed sediment flux to tide elevation, showing: (a), $q_{c}^{\prime} ;(\mathrm{b}), q_{s k}^{\prime}$; (c), $q_{a s}^{\prime}$; and (d), $q^{\prime}$. The wave period, incident angle and period are kept as $H_{r m s}=1.1$ $\mathrm{m}, \theta=11^{\circ}$ and $T=7 \mathrm{~s}$. The zero contour line is highlighted with the thick black dashed line. The horizontal black dashed line corresponds to mean tide. Red vertical dashed lines indicate the shoreward and seaward end of initial nourishment. The yellow contour lines show the wave energy dissipation $\left(\mathcal{D}_{w}\right)$. 
$\sim 6$ months of hourly observed hydrodynamical data (Fig. 5). The resulting evolution of the nourishment is shown in Fig. 14.

Fig. 14(a) shows the variation of $q^{\prime}$ in time and space in the vicinity of the initial nourishment location. Initially (Nov 1993) non-zero $q^{\prime}$ is limited to the region of the initial nourishment. Gradually the region of $\left|q^{\prime}\right|>0$ extends shoreward (there is very little deviation in $q^{\prime}$ seaward of the initial nourishment, which is therefore not shown). $q^{\prime}$ is mostly positive (i.e. onshore sediment transport due to the nourishment) for most of the six months in the initial nourishment region; any negative durations correspond to larger wave heights, consistent with the sensitivity study. The only prominent negative $q^{\prime}$ regions occur in the trough between the middle and inner bar-therefore shoreward of the initial nourishment-during energetic wave conditions. This is due to increased wave energy dissipation on the nourishment leading to less wave energy being available for onshore sediment movement in the trough, resulting in relative offshore sediment flux. Over the last two months, when wave heights diminish, we can see almost entirely onshore perturbed sediment flux. During the last two months the most intense perturbed sediment dynamics gradually shifts over into the region shoreward of the initial nourishment region, indicative of nourishment migration.

In Fig. 14(b) we plot the sediment flux divergence. Because differentiation is an un-smoothing operation this plot shows more small scale fluctuations, but the overall picture is of positive divergence (erosion) in the initial nourishment region, and negative divergence (deposition) in the region immediately shoreward. This also indicates a migration of the nourishment shoreward. Although sediment diffusion is excluded from this picture, each $q^{\prime}$ has been influenced by diffusion previously, so this effect is present too.

All physical processes are included in Fig. 14(c), which shows the evolution of the perturbation. We can see its onshore movement and relatively static seaward boundary, along with a gradual diffusion.

In Fig. 15 we plot the path of the centre of mass $\left(x_{M}(t)\right)$ of the simulated nourishment (black line), where:

$$
x_{M}(t)=\frac{\int_{0}^{2400 \mathrm{~m}} b(x, t) x \mathrm{~d} x}{\int_{0}^{2400 \mathrm{~m}} b(x, t) \mathrm{d} x}
$$

(following Roos et al., 2008, who examined a pit). Although there are fluctuations in the migration rate, a fairly steady onshore average migration can be 
(a)

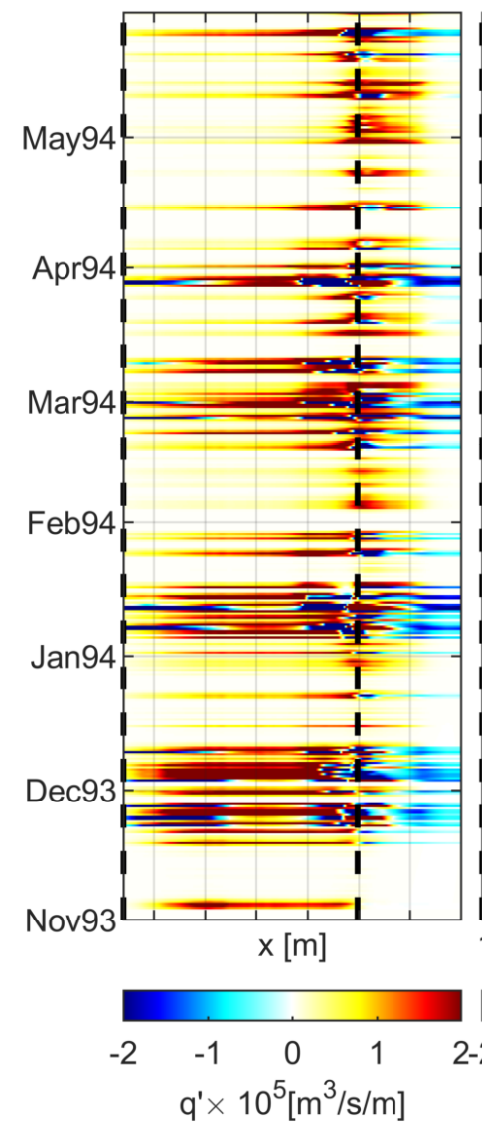

(b)

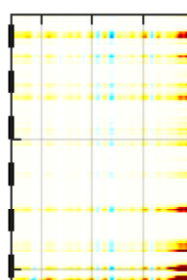

(c)

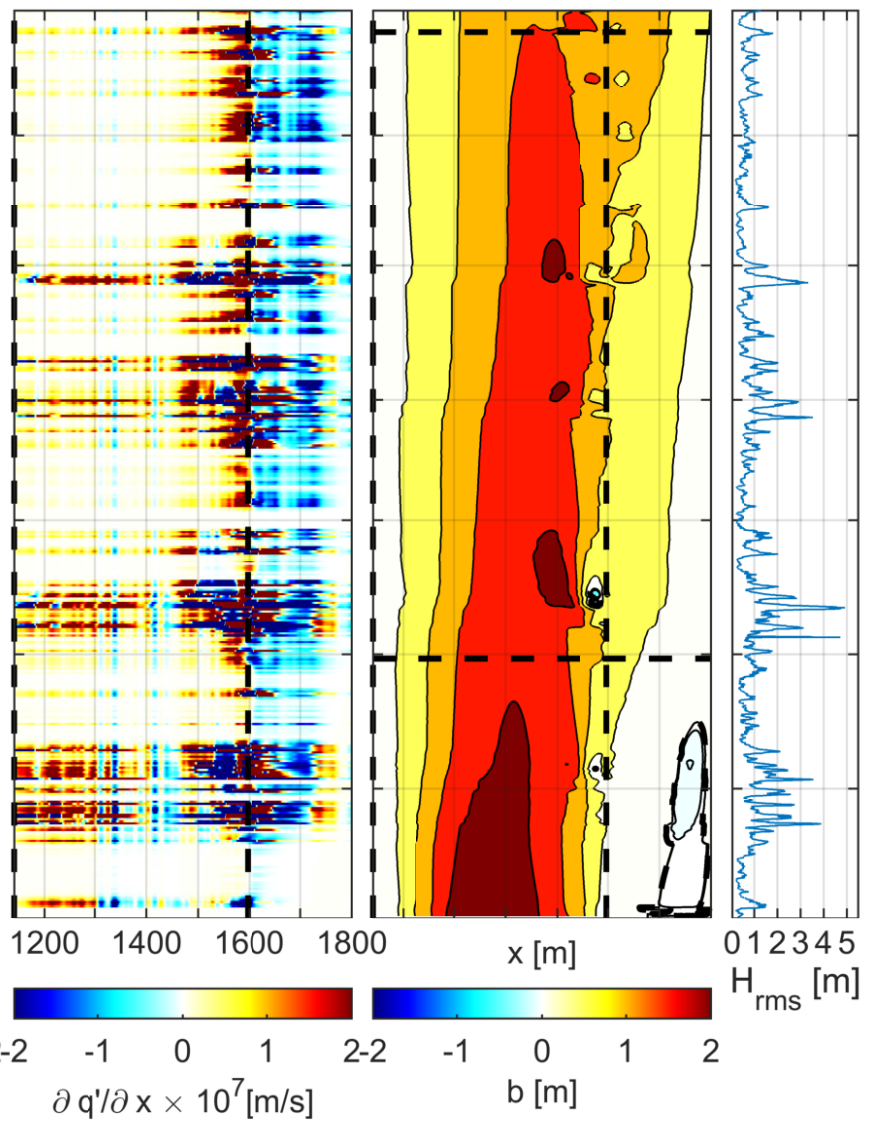

(d)

Figure 14: The evolution of: (a), sediment transport perturbation $\left(q^{\prime}\right)$; (b), cross-shore gradient of $q^{\prime}\left(\frac{\partial q^{\prime}}{\partial x}\right)$; (c), nourishment $(b)$; and (d), offshore wave heights $\left(H_{r m s}\right)$. The vertical thick black dashed lines refer to the seaward and shoreward end of the initial nourishment. The horizontal dashed lines in (c) indicate the time of sea bed observations.

observed (black line). There are two notable events where offshore migration can clearly be seen: January 10 and March 27. These days are notable for (January 10$)$ very high wave height $\left(H_{r m s} \approx 4.9 \mathrm{~m}\right)$ and long period $\left(T_{p} \approx 15.5 \mathrm{~s}\right)$ waves; and (March 27) fairly high wave height $\left(H_{r m s} \approx 3.2 \mathrm{~m}\right)$ and quite long period $\left(T_{p} \approx 11.5 \mathrm{~s}\right.$ ) waves (see Fig. 5 or Fig. $\left.14(\mathrm{~d})\right)$. The mean migration rate

$$
\overline{c_{M}}=\frac{1}{\tau} \int_{t_{0}}^{t_{0}+\tau} \frac{d}{d t} x_{M}(t) d t \approx 7.02 \mathrm{~m} / \text { month } \approx 0.234 \mathrm{~m} / \text { day }
$$




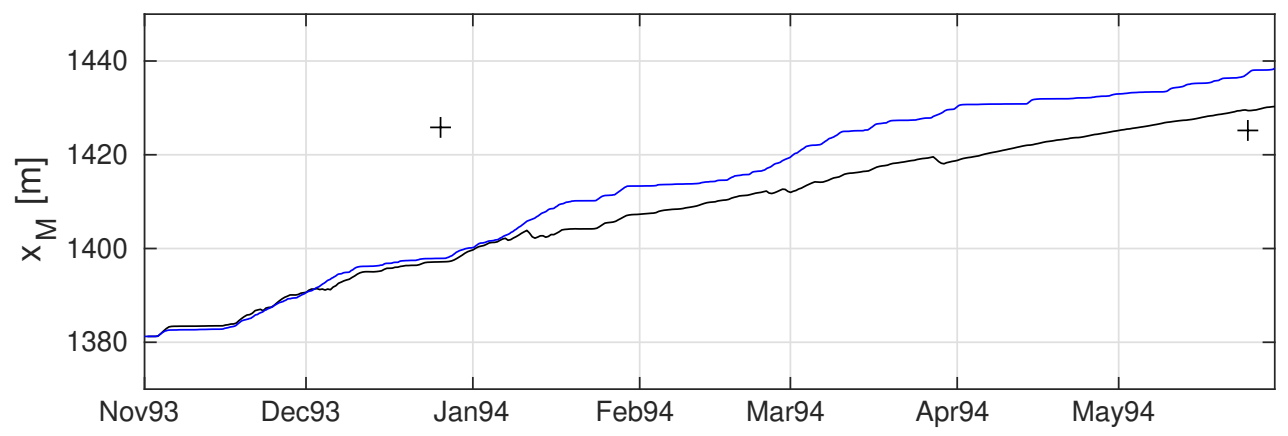

Figure 15: The migration of the nourishment as measured by $x_{M}(t)$ (black line), the centre of mass of the simulated nourishment; and $x_{n}(t)$ (blue line), the path calculated using the spatially averaged linear migration rate, $c_{n}(t)$. Crosses denote the observed centre of mass of the nourishment, $x_{M, o b s}$, found using the pre-nourishment profile as a reference bathymetry, at the two times at which subsequent measured cross-shore bathymetries exist. For the final $x_{M, o b s}$ value the calculation is as in Eq. [19, but for the intermediate value the integration is to $1900 \mathrm{~m}$ only.

where $\tau$ is the duration of the simulation, and $t_{0}$ corresponds to the start of the simulation showed in Fig. 14 , i.e. Nov. 1993. We can compare this to the average linear $c_{n}$ from Fig. 7 If we restrict the average to the initial nourishment region, and time average according to observed $H_{r m s}$, we get

$$
\overline{c_{n}}=\frac{1}{\tau} \int_{t_{0}}^{t_{0}+\tau} c_{n}(t) d t=\frac{1}{\tau} \int_{t_{0}}^{t_{0}+\tau} \int_{1140 \mathrm{~m}}^{1600 \mathrm{~m}} c_{n}\left(x, H_{r m s}(t)\right) d x d t \approx 0.272 \mathrm{~m} / \text { day } .
$$

This value is fairly similar to $\overline{c_{M}}$. In Fig. 15 (blue line) we plot the corresponding nourishment position using $c_{n}(t)$ :

$$
x_{n}(t)=x_{M}\left(t_{0}\right)+\int_{t_{0}}^{t_{0}+t} c_{n}\left(t^{\prime}\right) d t^{\prime}
$$

It is immediately apparent that $x_{n}(t)$ is a very good approximation to $x_{M}(t)$ up until the first aforementioned offshore propagation event. Thereafter the two positions diverge to some extent. Prior to the January $10^{\text {th }}$ event the $x_{n}$ and $x_{M}$ evolutions are very close, implying little overall bed change has taken place. After the event the details of the two time developments no longer correspond so closely.

It is instructive to examine this a little further. In Fig. 16 we show the effect of storms and calm periods during the simulation (a storm being defined here as an event for which $H_{r m s}>2 \mathrm{~m}$ continuously for at least 3 hours). In 


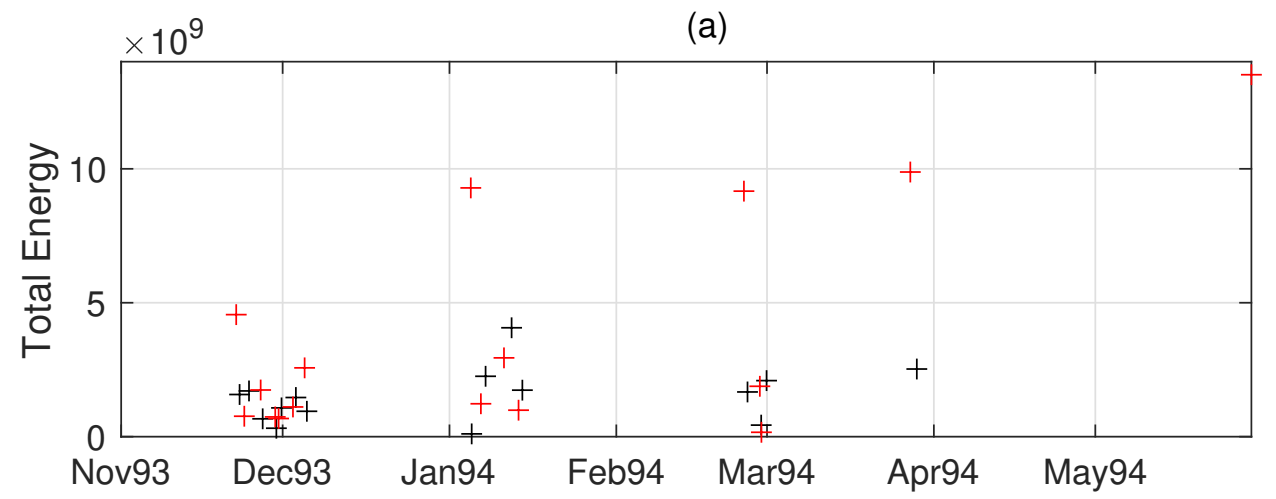

(b)

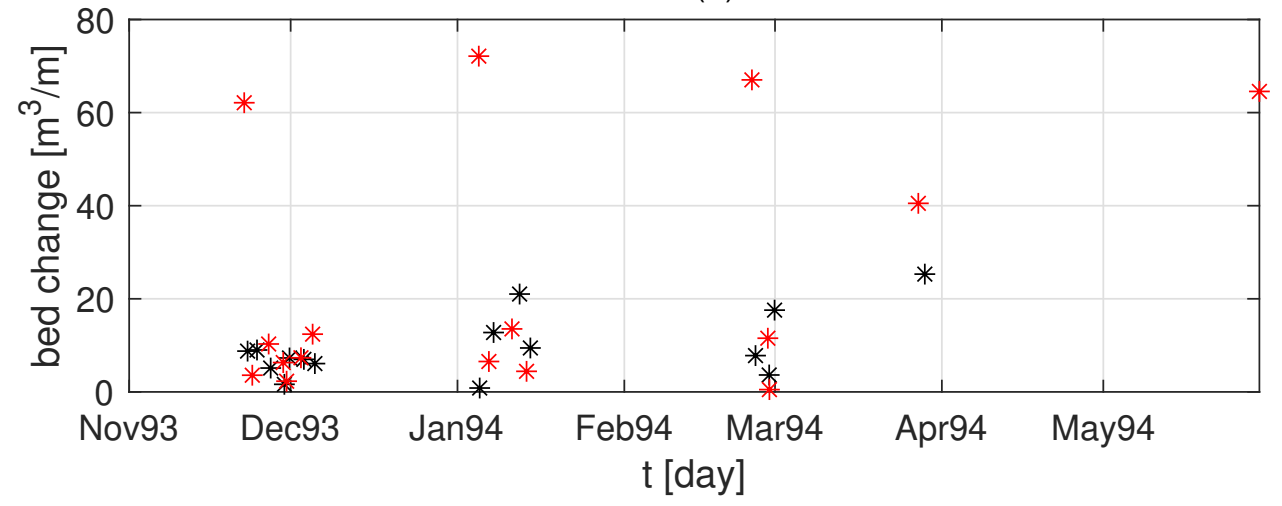

Figure 16: (a) Total wave energy entering the initial nourishment region during a storm (black crosses): $\int_{t_{b}}^{t_{e}} E c_{g} \cos \theta(x=1140 m, t) d t$, where $t_{b}\left(t_{e}\right)$ is time when $H_{r m s}$ first exceeds (subsequently falls below) the threshold; and during a calm period (red crosses, $t_{b}$ and $t_{e}$ are reversed). (b) Volume of bed change per $\mathrm{m}$ alongshore in the initial nourishment region due to a storm (black asterisks): $\int_{1140 m}^{1600 m}\left|b\left(x, t_{e}\right)-b\left(x, t_{b}\right)\right| d x$; and during a calm period (red asterisks, $t_{b}$ and $t_{e}$ are reversed). A storm is defined here as an event for which $H_{r m s}>2 \mathrm{~m}$ continuously for at least 3 hours, and calm periods are the intervals in between the storms). 
Fig. 16(a) the energy entering the initial nourishment region during each storm or calm duration is plotted. Unsurprisingly, largest energy inputs are during the extended calm periods (low energy densities for long durations). The next largest inputs are the large storms, the two largest (January 10 and March 27), corresponding to the aforementioned offshore migrating $x_{M}$ events, possessing the largest energies. In Fig. 16(b) we show the corresponding net bed change (absolute value), and there is a rough correspondence between large total energy inputs and net bed change. If we look back at Fig. 15 we see that it is during the storm events that the nonlinear migration rate (as indicated by $x_{M}(t)$ ) departs from the linear, small amplitude one (as indicated by $x_{n}(t)$ ), typically in an offshore movement of $x_{M}$. This offshore movement of $x_{M}$ is consistent with offshore sediment transport and migration for higher wave energy density. However, the $\overline{c_{n}}(t)$ depends only on the small amplitude $c_{n}(x, t)$ in the initial nourishment region, and regardless of $H_{r m s}$, this is likely to remain positive (see Fig. 7), hence the divergence during these events.

In Fig. 17 we can see the simulated bed change (dashed lines) which are compared with field observations (solid lines). The most general point to note is that sediment is eroded on the seaward side of the nourishment and deposited onto the middle bar and locations further shoreward, consistent with Fig. 14 and that this is also what is observed in the field. Closer inspection reveals regions of lesser and greater discrepancy. Seaward of the initial nourishment both observations and simulations reveal little change, and in the offshore portion of the initial nourishment there is similarly reasonably close correspondence between simulations and observations. Some significant discrepancies emerge in the vicinity of the middle bar. Although the simulated peaks do grow, as observed, at both Dec 93 and May 94 the simulated peak remains almost at the original middle bar location, whereas the observed one migrates. The filling in of the trough between middle and inner bars is reproduced by the model, but it is slower than in reality. Finally, on the seaward side of the inner bar erosion is evident by May 94, which is mostly not reproduced by the model. Note that the observed Dec 93 profile is curtailed at $x \approx 1900 \mathrm{~m}$, because shoreward of that the data is unreliable.

The model skill is evaluated quantitatively through a "Brier skill score" type parameter (van Rijn et al., 2003, Fernández-Mora et al., 2015) which is defined as:

$$
S=1-\frac{\int_{x_{1}}^{x_{2}}\left(z_{b, s i m}(x)-z_{b, o b s}\right)^{2} \mathrm{~d} x}{\int_{x_{1}}^{x_{2}}\left(z_{b, o b s}(x)-z_{b, 0}\right)^{2} \mathrm{~d} x},
$$


(a)

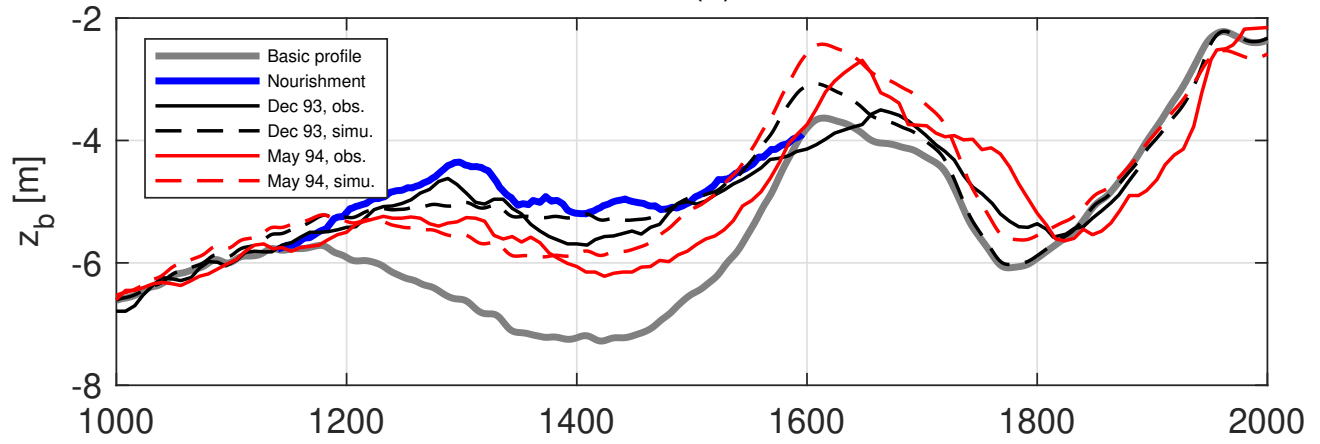

(b)

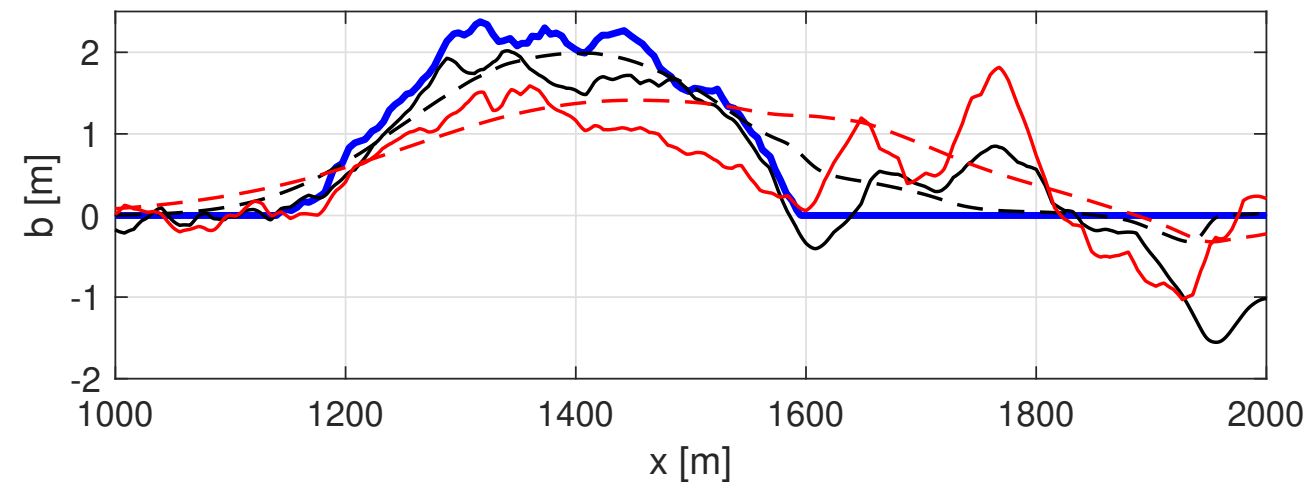

Figure 17: Comparison of the simulated and observed bed levels for the Terschelling nourishment, during (Dec 93) and at the end of (May 94) the simulation. (a) background profile + nourishment. (b) nourishment only (in the case of the observations, the initial background profile is subtracted. 
where $z_{b, s i m}$ and $z_{b, o b s}$ are simulated and observed bed level in May 1994. $x_{1}=$ $1000 \mathrm{~m}$ and $x_{2}=2000 \mathrm{~m}$. $S=1.0$ indicates a perfect match between simulation and observation. A skill of $S=0.52$ is achieved by this model.

Finally, in Fig. 15 we also plot the centre of mass of the observed morphological evolution, with respect to the Nov 93 pre-nourishment profile. There are only two estimates, based on the two measured profiles. We see a significantly faster onshore migration based on the Dec 93 observation than that simulated or based on the linear kinematics, but similar observed and simulated migration by May 94 .

\section{Discussion}

\subsection{Linear and nonlinear kinematics}

The migration rates $c_{n}(t)$ and $c_{M}(t)$ are apparently closely related. This implies that for relatively low energy conditions, which predominate over extended durations, we may use linear theory to accurately predict an average location for a shoreface nourishment without simulating the nourishment evolution itself. The results shown here are merely for an average $\overline{c_{n}}$ calculated over the extent of the initial nourishment. Since $c_{n}$ can be calculated for the whole profile the approach is extendable if the nourishment extent is similarly modified (once again using $\left.c_{n}(x, t)\right)$. Storm conditions, however, are likely to induce a qualitative change, because the presence of the nourishment transforms wave conditions during the storm, which is what we observe. However, it is straightforward to recalculate $c_{n}$ with a proposed nourishment in place, and thereby arrive at an estimate that is valid for storm waves, until the nourishment propagates away from the initial placement region.

Linked to this is the underlying change in the original bathymetry. A large enough change will render the NaaP approach invalid. Observations of transects from Terschelling seem to point to the pre-nourishment cross-shore profile being recovered after 6 years (Grunnet and Ruessink, 2005). This implies that the background profile is persistent, notwithstanding Summer / Winter variations and / or oblique bar migration. We also use the second moment of the nourishment to estimate the diffusion coefficient as

$$
\gamma_{M, o b s} \approx \frac{\int \Delta b\left(x-x_{M}\right)^{2} d x}{2 \Delta t \int b d x}
$$


We obtain $\gamma_{M, o b s} \approx 1.8 \times 10^{-3} \mathrm{~m}^{2} / \mathrm{s}$ for the change from the start of the nourishment to Dec 93. This result gives an indication that our chosen $\gamma$ is smaller than that observed. However, other numerical experiments considering a range from $3.5 \times 10^{-4}$ to $8 \times 10^{-4} \mathrm{~m}^{2} / \mathrm{s}$ (not shown) indicate little difference to results in the upper range of these values, which implies that using the larger value here probably would not make a significant difference to the simulations. From Dec 93 to May 94, in contrast, we get $-2.0 \times 10^{-3}$. This anti-dissipative result is perhaps not surprising considering the change in the observed profile in between these dates, and seems to provide evidence that the background profile has evolved by this date, whether in a purely $1 \mathrm{D}$ sense, or in $2 \mathrm{D}$ (see also $\S 5.2$. We also note that, although further work is required to evaluate for what duration the approach can remain viable in general, the deviation of $c_{n}$ and $c_{M}$ would seem to be a necessary condition.

The estimates of $x_{M, o b s}$ of Fig. 15 show close (May 94) and poor (Dec 93) correspondence with the model results (both $x_{M}$ and $x_{n}$ ). It should be noted that the profile of Dec 93 is only used up to $1900 \mathrm{~m}$. This is because shoreward of this point the profile exhibits a straight line segment, which seems likely to correspond to missing data. Including this section moves $x_{M, o b s}$ offshore of its initial value, which seems to support the decision not to include this section. Excluding from the calculation of $x_{M, o b s}$ for May 1994 the portion of the domain $x>1900 \mathrm{~m}$ also yields a larger $x_{M, o b s}$ value, consistent with the over-predicted value of $x_{M, o b s}$ observed for December 1993 in Fig. 15.

\subsection{Model limitations}

As noted earlier, we seek to capture the nourishment morphodynamics rather than attempt a model validation. Nonetheless, it is instructive to discuss the possible reasons for observed model-data discrepancies.

We do not consider here the effects of wave set-up. This effect is likely to be limited in the cross-shore, because we consider a shoreface nourishment and so exclude the typical shoreline maximum in set-up. There are other mechanisms for onshore sediment transport that we do not consider. The only two that could have an impact for the Terschelling case are sediment mobilisation by the injection of breaking-induced turbulence (e.g. Zhou et al. 2017) and phaserelated effects (e.g. Ruessink et al., 2009). The significance of these cannot be discarded, but the effects are not likely to dominate those that are included. Setting $u_{c r}=0$ will also have an effect. But we note that if we use the expression for $u_{c r}$ advocated by Soulsby (1997) this threshold is exceeded for about $91 \%$ 
of all points in the model $(x, t)$ domain, indicating that setting $u_{c r}=0$ is a reasonable approximation.

The down-slope effect of gravity on sediment is accounted for through a linear diffusion term with a constant coefficient. The presence of wave stirring of different intensities (see e.g. Larson and Hanson, 2015) at different points along the cross-shore transect means that this is likely to be an oversimplification. Increased diffusion, particularly in regions of wave breaking, would be likely to result in some of the missing infilling of the inner trough and a reduction in the middle bar elevation, both more consistent with observation. But agreement in the outer trough would seem likely to be worse.

This model study also does not consider the effect of the difference in grain size between the nourishment and the native sand (Guillen and Hoekstra, 1997). This is because only the bed-load component of the Soulsby-van Rijn formula is included, and thresholds of movement omitted.

The assumption probably most likely to have an impact on the modeldata comparison is that of alongshore uniformity. According to Spanhoff et al. (1997), the yearly averaged longshore transport rate in the nearshore zone of Terschelling is about $1 \mathrm{Mm}^{3}$ /year, so, although the site is chosen because of its quasi-alongshore-uniform geometry (see Fig. 3 it would, nonetheless, not take a large alongshore divergence in radiation stresses to generate alongshore sediment flux gradients. van Duin et al. (2004) also observed bar straightening post-nourishment at Egmond-aan-Zee.

By taking the difference between pre- and post-nourished sea bed elevation and integrating over the cross-shore profile, we can examine the change in sediment volume (per $\mathrm{m}$ alongshore) over time. Immediately after the nourishment, this volume is $532.6 \mathrm{~m}^{3} / \mathrm{m}$ in excess of the pre-nourishment profile of October 1993. By December 1993, this value is reduced to $474.8 \mathrm{~m}^{3} / \mathrm{m}$. By May 1994 , it has dropped to $320.4 \mathrm{~m}^{3} / \mathrm{m}$. Because the simulation is limited to 6 months it seems likely that a significant proportion of this loss is due to alongshore sediment flux gradients. Moreover, most of the difference between modelled and observed profiles constitutes an over-prediction of bed level, which is consistent with this explanation.

\section{Conclusion}

The inclusion of wave streaming and depth-varying mean return flow into bed evolution equation yields physically consistent migration speeds for small 
bed perturbations: onshore in the shoaling zone and offshore where breaking occurs. Onshore migration is fastest where waves feel the bottom most prominently, prior to breaking. The equivalent small amplitude migration rates for the initial nourishment region of the Terschelling profile therefore shown onshore migrations in the trough region and offshore migrations on the bars that delineate the initial nourishment. Using the resulting 1D (cross-shore) nonlinear nourishment-as-a-perturbation (NaaP) concept, also including arbitrary angle of incidence and field validated energy dissipation description, sensitivity studies are carried on for the Terschelling nourished profile. It is found that wave height is the primary controlling parameter for the resultant perturbed sediment flux. Perturbed sediment fluxes are onshore up to a wave height threshold of about $1.5 \mathrm{~m}$, beyond which offshore perturbed sediment fluxes predominate. Wave period, tide level and wave angle are all secondary effects, variation in which yields no change in perturbed sediment flux direction for fixed wave height. Wave period is the most significant effect of these.

The first six months of the Terschelling nourishment evolution are reproduced by the fully nonlinear NaaP model. Recorded wave and tide signals are used to drive the model. It is shown that in calmer conditions a mean small amplitude migration rate of bed disturbances is a highly accurate predictor of the fully nonlinear migration rate (as described by the centre of mass of the nourishment). In storm periods the two predictors diverge, but still remain reasonably close. The reason for this is that the introduction of the nourishment yields wave breaking over the nourishment (formerly the trough) during storm conditions, whereas storm waves break on the bars in the original profile. The observed overall migration rate, again measured by the centre of mass of the nourishment, is well described by the fully nonlinear model. The correspondence between linear small amplitude and nonlinear migration rates offers the possibility of low-cost accurate predictions of short-to-medium term nourishment evolution.

The modelled profile evolution shows a moderately good reproduction of the observed one (Brier Skill Score $=0.52$ ). The inclusion of the streaming and the more accurate description of the mean flow in the model improved the Brier Skill Score from 0.46 to 0.52. Discrepancies between the simulated and observed results are thought primarily to result from the 1D nature of the model. Significant 2D effects are observed at the site, albeit most notably over a longer timescale (Grunnet and Ruessink, 2005). Loss of mass in the cross-shore profile seems to corroborate this. 


\section{Acknowledgements}

The support of the UK Engineering and Physical Sciences Research Council (EPSRC) under the MORPHINE project (grant EP/N007379/1) and of the University of Nottingham is gratefully acknowledged. We are grateful to prof. dr. Gerben Ruessink for providing the Terschelling data. We are also grateful to the suggestions of two anonymous reviewers, particularly with regard to the suggestion to look at the second moment.

\section{References}

Baldock, T., P. Holmes, S. Bunker, and P. V. Weert, Cross-shore hydrodynamics within an unsaturated surf zone, Coast. Eng., 34(3), 173 - 196, doi:10.1016/ S0378-3839(98)00017-9, 1998.

Battjes, J., and J. Janssen, Energy loss and set-up due to breaking of random waves, Coast. Eng. Proc., 1(16), 32, doi:10.9753/icce.v16.32, 1978.

Capobianco, M., H. Hanson, M. Larson, H. Steetzel, M. J. F. Stive, Y. Chatelus, S. Aarninkhof, and T. Karambas, Nourishment design and evaluation: applicability of model concepts, Coast. Eng., 47(2), 113 - 135, doi:10.1016/ s0378-3839(02)00123-0, 2002.

Chen, W., and N. Dodd, An idealised study for the evolution of a shoreface nourishment, Cont. Shelf Res., 178, 15 - 26, doi:10.1016/j.csr.2019.03.010, 2019.

De Swart, H. E., and D. Calvete, Non-linear response of shoreface-connected sand ridges to interventions, Ocean Dynamics, 53(3), 270-277, doi:10.1007/ s10236-003-0044-9, 2003.

Dean, R. G., and R. A. Dalrymple, Water Wave Mechanics for Engineers and Scientists, WORLD SCIENTIFIC, doi:10.1142/1232, 1991.

Fernández-Mora, A., D. Calvete, A. Falqués, and H. E. de Swart, Onshore sandbar migration in the surf zone: New insights into the wave-induced sediment transport mechanisms, Geophys. Res. Let., 42(8), 2869-2877, doi: 10.1002/2014GL063004, 2015.

Fuhrman, D. R., J. Fredsoe, and B. M. Sumer, Bed slope effects on turbulent wave boundary layers: 2. comparison with skewnes, asymmetry, and other effects, J. Geophys. Res., 114, C03,025, 2009. 
Grunnet, N. M., and B. Ruessink, Morphodynamic response of nearshore bars to a shoreface nourishment, Coast. Eng., 52(2), 119 - 137, doi:10.1016/j. coastaleng.2004.09.006, 2005.

Grunnet, N. M., D.-J. R. Walstra, and B. Ruessink, Process-based modelling of a shoreface nourishment, Coast. Eng., 51(7), 581 - 607, doi:10.1016/j. coastaleng.2004.07.016, 2004.

Grunnet, N. M., B. G. Ruessink, and D. Walstra, The influence of tides, wind and waves on the redistribution of nourished sediment at terschelling, Coastal Eng., 52, 617-631, 2005.

Guillen, J., and P. Hoekstra, Sediment distribution in the nearshore zone: grain size evolution in response to shoreface nourishment (Island of Terschelling, The Netherlands, Estuarine, Coastal and Shelf Science, 45, 639-652, 1997.

Hamm, L., M. Capobianco, H. H. Dette, A. Lechuga, R. Spanhoff, and M. J. F. Stive, A summary of european experience with shore nourishment, Coast. Eng., 47(2), 237 - 264, doi:10.1016/S0378-3839(02)00127-8, 2002.

Hillen, R., and P. Roelse, Dynamic preservation of the coastline in the netherlands, J. Coast. Conserv., 1(1), 17-28, doi:10.2307/25098187, 1995.

Hoekstra, P., K. T. Houwman, A. kroon, P. V. Vessem, and B. G. Ruessink, The NOUTEC experiment of Terschelling: process-oriented monitoring of a shoreface nourishment (1993-1996), in Proc. 1st Int. Conf. on Coastal Dynamics, edited by A. Arcilla, M. J. F. Stive, and N. C. Kraus, pp. 402-416, ASCE, 1994.

Kranenburg, W. M., J. S. Ribberink, R. E. Uittenbogaard, and S. J. M. H. Hulscher, Net currents in the wave bottom boundary layer: On waveshape streaming and progressive wave streaming, J. Geophys. Res. : Earth Surf., 117(F3), doi:10.1029/2011JF002070, 2012.

Larson, M., and H. Hanson, Model of the evolution of mounds placed in the nearshore, Journal of Integrated coastal zone management, 15(1), 21 - 33, doi:10.5894/rgci530, 2015.

Longuet-Higgins, M. S., Mass transport in water waves., Trans. Royal Soc. London Ser. A., 245, 535-581, 1953. 
Longuet-Higgins, M. S., The mechanics if the boundary-layer near the bottom in a progressive wave. appendix to Russell, R.C.H. and Osorio, J.D.C.: An experiment investigation of drift profiles in a closed channel., in Proc. 6th Int. Conf. Coast. Eng. Miami, FL., pp. 184-193, 1957.

Phillips, O. M., The Dynamics of the Upper Ocean, second ed., Cambridge Univ. Press, Cambridge, 1977.

Roelvink, D., and A. Reniers, A Guide to Modeling Coastal Morphology, WORLD SCIENTIFIC, doi:10.1142/7712, 2011.

Roos, P. C., and S. J. M. H. Hulscher, Large-scale seabed dynamics in offshore morphology: Modeling human intervention, Rev. Geophys., 41(2), 1010, doi:10.1029/2002RG000,120, 2003.

Roos, P. C., S. J. M. H. Hulscher, M. A. F. Knaapen, and R. M. J. van Damme, The cross-sectional shape of tidal sand banks: modeling and observations, $J$. Geophys. Res., F02003, 2004.

Roos, P. C., S. J. M. H. Hulscher, and H. J. de Vriend, Modelling the morphodynamic impact of offshore sandpit geometries, Coastal Eng., 55, 704-715, 2008.

Ruessink, B., D. Walstra, and H. Southgate, Calibration and verification of a parametric wave model on barred beaches, Coast. Eng., 48(3), 139 - 149, doi:10.1016/S0378-3839(03)00023-1, 2003.

Ruessink, B. G., T. J. J. van den Berg, and L. C. van Rijn, Modeling sediment transport beneath skewed asymmetric waves above a plane bed, J. Geophys. Res., 114(C11021), doi:10.1029/2009JC005,416, 2009.

Ruessink, B. G., G. Ramaekers, and L. C. van Rijn, On the parameterization of the free-stream non-linear wave orbital motion in nearshore morphodynamic models, Coast. Eng., 65, 56 - 63, doi:10.1016/j.coastaleng.2012.03.006, 2012.

Soulsby, R., Dynamics of marine sands, a manual for practical applications, 249 pp., Thomas Telford, 1997.

Spanhoff, R., E. J. Biegel, J. V. Graaff, and P. Hoekstra, Shoreface Nourishment at Terschelling, The Netherlands: Feeder berm or breaker berm?, in Proc. 3rd Int. Conf. on Coastal Dynamics, edited by E. B. Thornton, pp. 863-872, ASCE, 1997. 
Süli, E., and D. F. Mayers, An Introduction to Numerical Analysis, Cambridge University Press, doi:10.1017/CBO9780511801181, 2003.

Svendsen, I. A., Introduction to nearshore hydrodynamics, 722 pp., World Scientific, 2006.

van Duin, M. J. P., N. R. Wiersma, D. J. R. Walstra, L. C. van Rijn, and M. J. F. Stive, Nourishing the shoreface: observations and hindcasting of the Egmond case, The Netherlands, Coast. Eng., 51(8), 813 - 837, doi:10.1016/ j.coastaleng.2004.07.011, coastal Morphodynamic Modeling, 2004.

Van Leeuwen, S. M., N. Dodd, D. Calvete, and A. Falqués, Physics of nearshore bed pattern formation under regular or random waves, J. Geophys. Res., 111(F01023), doi:10.1029/2005JF000,360, 2006.

van Leeuwen, S. M., N. Dodd, D. Calvete, and A. Falqués, Linear evolution of a shoreface nourishment, Coast. Eng., 54(5), 417 - 431, doi:10.1016/j. coastaleng.2006.11.006, 2007.

van Rijn, L., D. Walstra, B. Grasmeijer, J. Sutherland, S. Pan, and J. Sierra, The predictability of cross-shore bed evolution of sandy beaches at the time scale of storms and seasons using process-based profile models, Coast. Eng., 47(3), 295 - 327, doi:10.1016/S0378-3839(02)00120-5, 2003.

van Rijn, L. C., J. S. Ribberink, J. van der Werf, and D. J. R. Walstra, Coastal sediment dynamics: recent advances and future research needs, Journal of Hydraulic Research, 51(5), 475-493, 2013.

Zhou, Z., T.-J. Hsu, D. Cox, and X. Liu, Large-eddy simulation of wave-breaking induced turbulent coherent structures and suspended sediment transport on a barred beach, J. Geophys. Res., 122, 207-235, 2017.

\section{Appendix A. wave driven current profile}

Following Roelvink and Reniers (2011), we assume a linear distribution of cross-shore shear stress $\left(\tau_{x}(z)\right)$ in vertical direction ( $z$, positive upward),

$$
\tau_{x}(z)=\tau_{s x}+\frac{\tau_{s x}-\tau_{b x}}{h z},
$$


where $\tau_{s x}$ and $\tau_{b x}$ are the surface and bottom shear stress, forced by roller dissipation, which is given by:

$$
\tau_{s x}=\frac{\mathcal{D}_{r}}{c} \cos \theta
$$

The velocity and shear stress satisfy

$$
\mu_{v} \frac{\partial u_{E}}{\partial z}=\frac{\tau_{x}}{\rho},
$$

where $u_{E}$ is the Eulerian velocity. The vertically eddy viscosity $\mu_{v}$ has a parabolic profile

$$
\mu_{v}=-k_{a} v_{*} z \frac{z+h}{h},
$$

with $k_{a}$ being the von Karman constant. $v_{*}$ is the shear velocity, consisting of a constant part and a breaking dependent part, i.e., $v_{*}=\frac{\mu}{Z_{0} k_{a}}+\sqrt{\frac{\tau_{s x}}{\rho}}$ with $\mu=0.025 \mathrm{~m}^{2} \mathrm{~s}^{-1}$ being the constant viscosity of water and $Z_{0}=1 \mathrm{~m}$ a vertical length scale. Therefore, $u_{E}$ can be written as

$$
u_{E}=-\frac{1}{\rho k_{a} v_{*}}\left(\tau_{s x} \ln \frac{z}{z_{0}-h}-\tau_{b x} \ln \frac{h+z}{z_{0}}\right),
$$

using the bed boundary condition, i.e., $u_{E}=0$ at $z=-h+z_{0}\left(z_{0}\right.$ is the bed roughness).

The vertical integrated current should balance the onshore flux ( $u_{\text {onshore }}=$ $\left.\frac{E_{w}+2 E_{r}}{\rho h c}\right)$ due to stokes drift and roller. This leads to

$$
-\frac{1}{\rho k_{a} v_{*}}\left(\tau_{b x}\left(1-\ln \frac{h}{z_{0}}\right)-\tau_{s x}\right)+u_{\text {onshore }}=0,
$$

and furthermore,

$$
\tau_{b x}=\frac{\tau_{s x}+\rho k_{a} v_{*} u_{\text {onshore }}}{1-\ln \left(h / z_{0}\right)} .
$$

Now we can substitute the expression of bottom shear stress into Eq. A.5 to obtain the vertical profile of $u_{E}$. The $u_{L}$ is then simply the superposition of $u_{E}$ and $u_{\text {stokes. }}$. The flow velocity evaluated at $0.1 \mathrm{~m}$ above the bed is used for the calculation of $q_{c}$. As shown in Fig. A.18, the near bed current calculated with Eq. (13) has a positive value in the shoaling zone and is negative in the surf zone. 

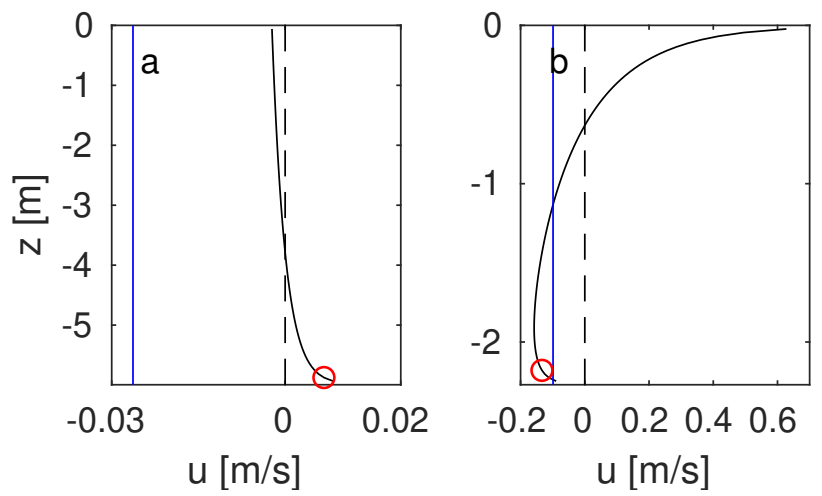

Figure A.18: Vertical distribution of $u_{L}$ (black solid curve) at: (a), $x=1100 \mathrm{~m}$, shoal zone; and (b), $x=1970 \mathrm{~m}$, surf zone. Wave of representative characteristics (as in 4.4 ) and basic sea bed profile are used to obtain this plot. The vertical blue solid line represents the depth averaged return flow (calculated with Eq.15 in Chen and Dodd (2019)). The red circle denotes the evaluated near bed current for the calculation of $q_{c}$. 